\title{
ELER software - a new tool for urban earthquake loss assessment
}

\author{
U. Hancilar ${ }^{1, *, * *}$, C. Tuzun ${ }^{1}$, C. Yenidogan ${ }^{1}$, and M. Erdik ${ }^{1}$ \\ ${ }^{1}$ Department of Earthquake Engineering, Kandilli Observatory and Earthquake Research Institute (KOERI), \\ Boğaziçi University, Istanbul, Turkey \\ *now at: European Laboratory for Structural Assessment (ELSA), Institute for the Protection and Security \\ of the Citizen (IPSC), Joint Research Centre of the European Commission (EC-JRC), Ispra, Italy \\ ** Invited contribution by U. Hancilar, recipient of the EGU Young Scientists Outstanding Poster Paper Award 2009.
}

Received: 6 July 2010 - Revised: 24 November 2010 - Accepted: 1 December 2010 - Published: 22 December 2010

\begin{abstract}
Rapid loss estimation after potentially damaging earthquakes is critical for effective emergency response and public information. A methodology and software package, ELER-Earthquake Loss Estimation Routine, for rapid estimation of earthquake shaking and losses throughout the Euro-Mediterranean region was developed under the Joint Research Activity-3 (JRA3) of the EC FP6 Project entitled "Network of Research Infrastructures for European Seismology-NERIES". Recently, a new version (v2.0) of ELER software has been released. The multi-level methodology developed is capable of incorporating regional variability and uncertainty originating from ground motion predictions, fault finiteness, site modifications, inventory of physical and social elements subjected to earthquake hazard and the associated vulnerability relationships. Although primarily intended for quasi real-time estimation of earthquake shaking and losses, the routine is also equally capable of incorporating scenario-based earthquake loss assessments.

This paper introduces the urban earthquake loss assessment module (Level 2) of the ELER software which makes use of the most detailed inventory databases of physical and social elements at risk in combination with the analytical vulnerability relationships and building damage-related casualty vulnerability models for the estimation of building damage and casualty distributions, respectively. Spectral capacitybased loss assessment methodology and its vital components are presented. The analysis methods of the Level 2 module, i.e. Capacity Spectrum Method (ATC-40, 1996), Modified Acceleration-Displacement Response Spectrum Method (FEMA 440, 2005), Reduction Factor Method (Fajfar, 2000) and Coefficient Method (ASCE 41-06, 2006), are applied to the selected building types for validation and verification pur-
\end{abstract}

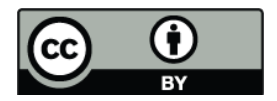

Correspondence to: $\mathrm{U}$. Hancilar (ufuk.hancilar@jrc.ec.europa.eu) poses. The damage estimates are compared to the results obtained from the other studies available in the literature, i.e. SELENA v4.0 (Molina et al., 2008) and ATC-55 (Yang, 2005). An urban loss assessment exercise for a scenario earthquake for the city of Istanbul is conducted and physical and social losses are presented. Damage to the urban environment is compared to the results obtained from similar software, i.e. KOERILoss (KOERI, 2002) and DBELA (Crowley et al., 2004). The European rapid loss estimation tool is expected to help enable effective emergency response, on both local and global level, as well as public information.

\section{Introduction}

Earthquake shaking and loss information is ultimately intended for dissemination in a timely manner to related agencies for the planning and coordination of post-earthquake emergency response. Earthquake losses might be assessed on a regional and/or an urban scale. Regional estimates of damage to built-environment and assessment of human losses can be achieved using region-specific theoretical/empirical vulnerability relationships in connection with regional inventories of physical and social elements exposed to risk. On an urban scale, more detailed inventories of elements at risk are required to be used with analytical vulnerability relationships for the estimation of earthquake losses. Grid based (geo-coded) inventories of building stock and demographic data are needed for urban earthquake loss assessment. For an urban level analysis, the data should, at minimum, include construction year, occupational type, construction material type and number of floors for each building class as well as the number of people residing at each geo-cell. Hence the sophistication and completeness level of inventories of elements at risk will determine the level of analysis that to be used in loss estimation. Comprehensive

Published by Copernicus Publications on behalf of the European Geosciences Union. 
evaluation of methodologies for rapid earthquake loss assessment as well as information about currently operating near-real-time global and local loss estimation tools can be found in Erdik et al. (2011). The present paper addresses spectral capacity-based loss estimation methodology for the assessment of earthquake losses in urban areas and its implementation in ELER software supported by some validation/verification studies.

The Joint Research Activity 3 (JRA3) of the EC FP6 Project NERIES (http://www.neries-eu.org/; Giardini et al. 2008) aimed at establishing rapid estimation of earthquake damages, casualties, shelters and food requirements throughout the Euro-Med Region. Within the scope of this activity, a rapid loss estimation tool, ELER Software (Erdik et al., 2008a, 2010; Hancilar et al., 2009; Sesetyan et al., 2009), was developed with researchers from Bogazici University-Kandilli Observatory and Earthquake Research Institute (KOERI), Imperial College (IC), NORSAR and Euro-Mediterranean Seismological Centre (EMSC). The ELER software incorporates both regional- and urban-scale almost real-time estimation of losses after a major earthquake in the Euro-Med region. The software package comprises a Hazard module and three loss estimation modules: Level 0, Level 1 and Level 2. The Hazard module basically produces earthquake shake maps in terms of selected ground motion parameters such as peak ground acceleration (PGA), peak ground velocity (PGV) and spectral acceleration $\left(S_{\mathrm{a}}\right)$, through region-specific ground motion prediction equations (GMPE). The shake mapping methodology is similar to the USGS Shake Map (Wald et al., 2005). For site-specific analysis, the Hazard module utilizes shear wave propagation velocity (e.g. average shear wave propagation velocity in $30 \mathrm{~m}$ depth of the medium, $\left.\mathrm{V}_{s-30}\right)$ distributions obtained from regional geology (Quaternary, Tertiary, Mesozoic (QTM) maps) or slope-based $\mathrm{V}_{s-30}$ maps (Allen and Wald, 2007). Following the estimation of the spatial distribution of selected ground motion parameters, earthquake losses (damage, casualty and economic) can be estimated at different levels of sophistication, namely Level 0 , 1 and 2, based on the availability of building inventory and demographic data (Demircioglu et al., 2009). The Level 0 module provides estimates of the number of casualties and their geographic distribution, either using regionally adjusted intensity-casualty or magnitude-casualty correlations and population distributions. The Level 1 module calculates regional estimates of building damage and casualty distributions based on the EMS98 (Grünthal, 1998) building vulnerability relationships and regional building inventory data bases and population distributions. Level 2 type analysis corresponds to a higher sophistication level in loss estimation methodology, in which the building damage and casualty distributions are obtained using analytical vulnerability relationships and building damage-related casualty vulnerability models, respectively. The Level 2 module of ELER (similar to HAZUS, 1999 and HAZUS-MH, 2003) essentially aims at assessing the earthquake risk (building damage, consequential human casualties and macroeconomic loss quantifiers) in urban areas. Spectral capacity-based vulnerability assessment methodology is utilized for building damage estimations. The following methods can be chosen for the calculation of performance point: Capacity Spectrum Method (ATC-40, 1996), Modified Acceleration-Displacement Response Spectrum Method (FEMA 440, 2005), Reduction Factor Method (Fajfar, 2000), Coefficient Method (ASCE 41-06, 2006). The inventory data for the elements at risk consist of grid (geo-cell) -based urban building and demographic inventories. For building grouping, the European building taxonomy developed by Lagomarsino and Giovinazzi (2006) within the EC FP5 RISK-UE project and model building types of HAZUS-MH (2003) is used. The software database not only includes building capacity and analytical fragility parameters for both building taxonomies, but the user also has the capability of defining custom capacity and fragility curves using the Building Database Creator (BDC) tool. Having calculated the damaged buildings by one of the above mentioned methods, casualties are estimated based on the number of buildings in different damage states and the casualty rates for each building type and damage level.

The ELER software provides a robust loss estimation methodology by making use of several well-tested methods known worldwide. Since it has been intended in its design process to develop a comprehensive tool for the estimation of earthquake losses, ELER starts to work by producing shaking maps that display the spatial distribution of selected ground motion intensity measures through region-specific GMPEs with appropriate site response modifications. It enables the user to assess damages to built-environment as well as estimate human casualties by directly incorporating the computed ground motion and by dealing with methodologies such as regionally adjusted intensity-casualty or magnitudecasualty correlations and intensity-based empirical vulnerability or spectral displacement-based analytical vulnerability relationships, which are at different levels of sophistication that commensurate with the availability of input data. The ELER software has also a few key noteworthy features within its IT capabilities. The software package coded and compiled in MATLAB environment is easy to install and to use in different operating systems such as Windows (x64), Linux (x86-64), Mac OS X, Solaris 64. All the analyses and calculations are performed by the computational and statistical toolboxes of MATLAB. However, the user does not need to have a MATLAB license to execute the analysis since the program works as a stand-alone tool. ELER has a graphical user interface (GUI) to input the data and to present the output. It also works from the command line interface which can be used for automated, scheduled or event triggered runs. The output is represented as damage and casualty maps and the results can be exported to popular GIS platforms for further elaboration and illustration purposes. Snapshots of the main screens of ELER's GUI are presented in Fig. 1. 


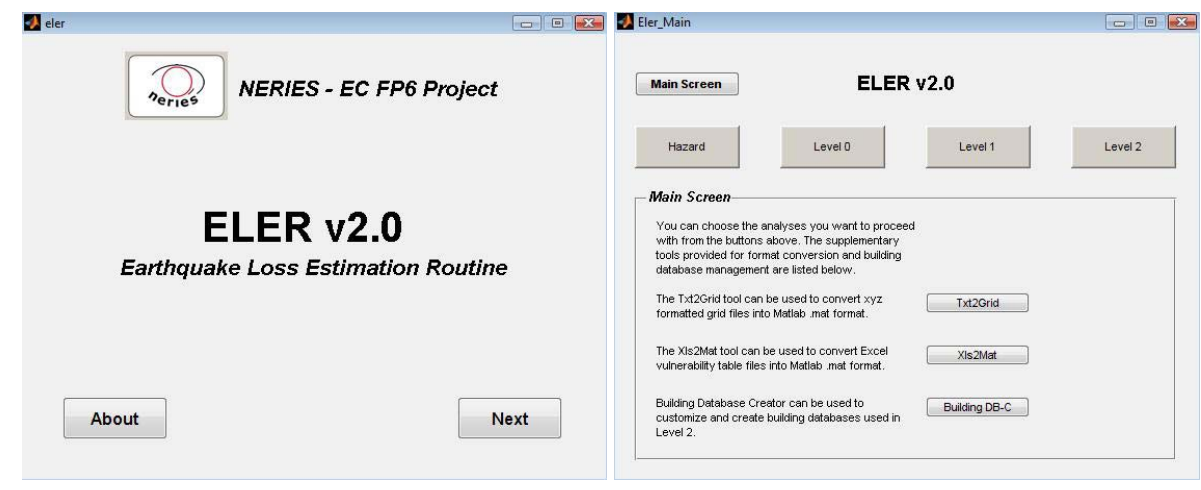

Fig. 1. Snapshots of the main screens of ELER's GUI.

The European rapid loss estimation tool is expected to help enable effective emergency response, on both local and global levels, as well as enabling public information. It has been selected for testing and utilisation in the implementation of the open-source global risk engine for GEM (Global Earthquake Model). The Level 2 module was used for the loss assessment case study of Los Angeles city (Crowley et al., 2010). ELER will also be used in the city scenario applications for selected cities such as Tehran, Karachi and Yerevan within the EMME (Earthquake Model of the Middle East Region) project. A new version of the software, ELER v3.0, is under development and it will contain two new modules. The economic loss module (Level 1 and Level 2) will estimate financial losses by translating the physical damage into total monetary loss using user-defined loss ratios and local estimates of building replacement costs. The pipeline damage module will estimate damages to urban pipeline systems such as potable water, wastewater and natural gas lines based on empirical correlations that relate the repair rates to the PGV distributions. The upcoming version will also enable the user to upload custom GMPEs.

In the present paper, spectral capacity-based loss estimation methodology for the assessment of earthquake losses in urban areas is addressed. Comprehensive information on the capacity spectrum-based building damage estimation methods as well as their implementation in ELER are provided in Sect. 2. Assessment of casualties is covered in Sect. 3. Section 4 is dedicated to example applications and a case study exercise by the ELER software. The reader is referred to Erdik et al. (2010) for further information on the Hazard, Level 0 and Level 1 modules of ELER and for applications not only under scenario events but also for loss estimations and comparisons with actual observations for past and recent earthquakes, such as the 1999 Kocaeli-Turkey Earthquake, the 1999 Athens-Greece Earthquake and the 2009 L'AquilaItaly Earthquake.

\section{Spectral capacity-based vulnerability and damage assessment methodology}

Vulnerability is defined as the degree of loss to a given element at risk or a set of such elements, resulting from the occurrence of a hazard. Vulnerability functions (or fragility curves) of an element at risk represent the probability that its response to earthquake excitation exceeds its various performance limit states based on physical and socio-economic considerations. For a population of buildings exposed to earthquake hazard, the vulnerability relationships relates the probability of exceedance of multiple damage limit states (or being in certain damage states) to given measures of the ground motion severity. The generic procedures used for developing earthquake vulnerabilities can be grouped as empirical (or observational) and analytical (or predicted). Combination of both empirical and analytical estimates might be considered as expert judgment (Erdik et al., 2008b, 2011). Analytical (or predicted) vulnerability refers to the assessment of expected performance of buildings based on calculation and building characteristics. The analytical method is applicable essentially to engineered buildings, whose earthquake performance can be analytically estimated. An analytical method or estimating seismic vulnerability using nonlinear pseudo-static structural analysis is described by Kircher et al. (1997), in which the lateral force versus lateral displacement curve of building structure, idealized as an equivalent nonlinear, single degree of freedom (SDOF) system, is obtained. This curve is transformed to the spectral displacement-spectral acceleration space to obtain the so-called capacity spectrum. Building capacity spectra vary between different buildings, reflecting structural types, local construction practices, and building code regulations.

The so-called Capacity Spectrum Method (ATC-40, 1996 and HAZUS, 1999), developed for the analytical assessment of structural vulnerabilities, evaluates the seismic performance of structures (represented by equivalent singledegree-of-freedom, SDOF, models) by comparing their structural capacity and the seismic demand curves drawn in 

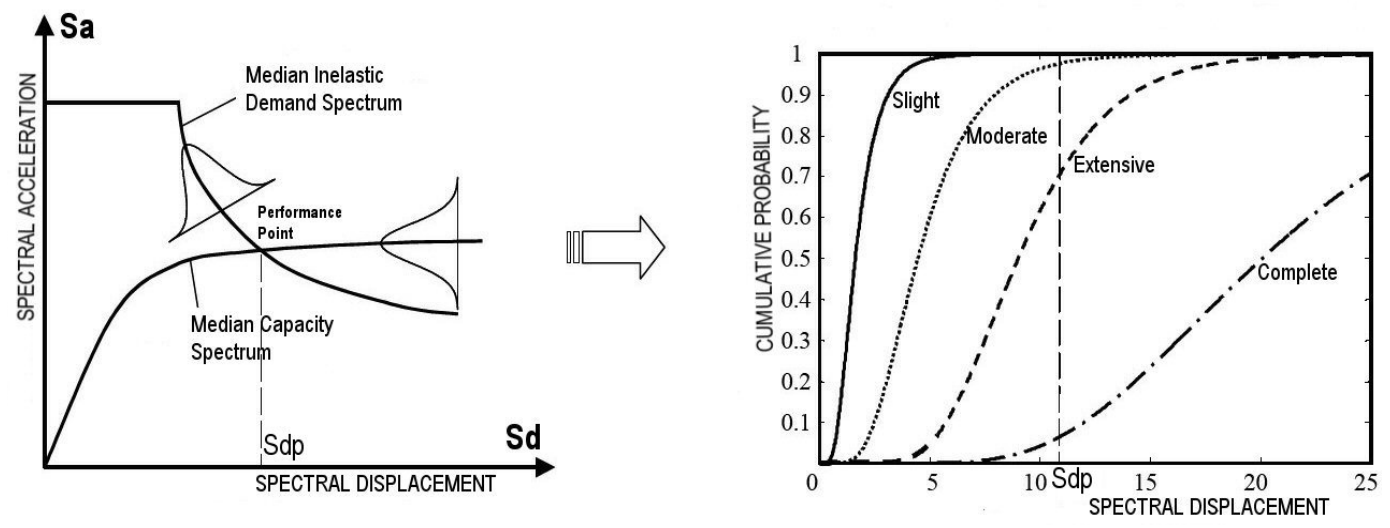

Fig. 2. Graphical representation of spectral capacity based vulnerability and damage assessment methodology: Building capacity and seismic demand spectra and estimation performance point (left), introduction of the performance point into the fragility curves and estimation of damage probabilities (right).

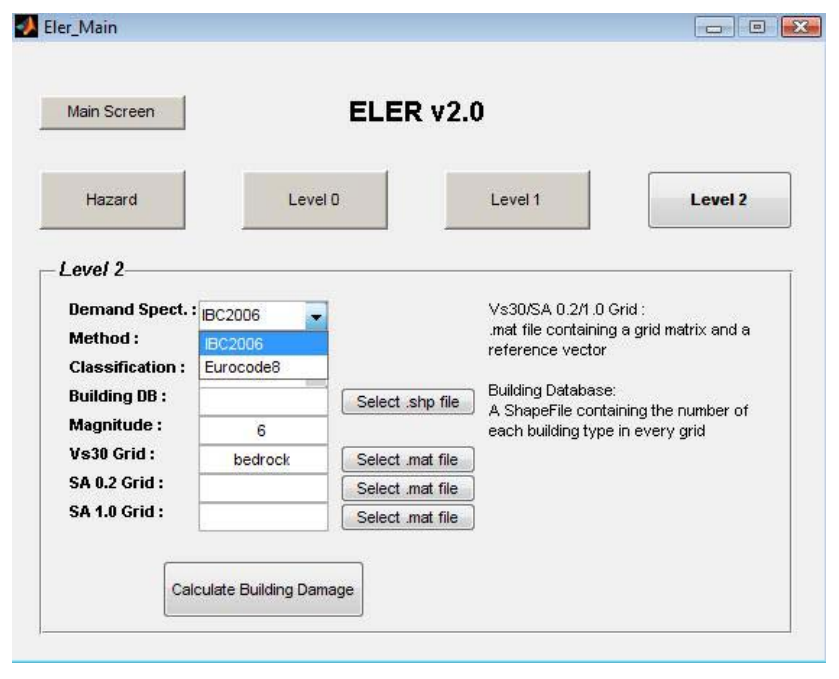

Fig. 3. Selection of response spectral shape for the calculation of seismic demand spectrum.

spectral acceleration $\left(S_{\mathrm{a}}\right)$ versus spectral displacement $\left(S_{\mathrm{d}}\right)$ coordinates (hence the terminology: capacity spectrum and demand spectrum). The key to this method is the reduction of 5\%-damped elastic response spectra of the ground motion (in $S_{\mathrm{a}}-S_{\mathrm{d}}$ or the so-called ADRS format) in order to take into account the inelastic behaviour of the structure under consideration. The performance of the building structure to earthquake ground shaking is then identified by the so-called "performance point" located at the intersection of the capacity spectrum of the equivalent non-linear single-degree-offreedom system and the earthquake demand spectrum. After estimation of the performance point, the damage is estimated through the use of fragility curves. Fragility curves calculate the probability of being equal or exceeding a damage state assuming log-normal distribution of damage.
A schematic description of the methodology is provided in Fig. 2. The inelastic acceleration-displacement spectrum for the ground motion (seismic demand spectrum) is superimposed on the capacity of a building (capacity spectrum) and the fragility relationship. The probability distributions, drawn over both the capacity and demand curves, indicate the associated uncertainty and randomness of performance. The intersection of these spectra gives the expected level of performance (performance point). As it can be seen from Fig. 2 there is a substantial uncertainty of the location of the performance point and the fragility curves should be able to characterize this probabilistic nature of the problem.

The capacity spectrum method is an approximate heuristic method which essentially assumes that a complex nonlinear multi-degree-of-freedom system such as a multi-story building undergoing severe plastic deformations during an earthquake can be modelled as an equivalent single degree of freedom system with an appropriate level of inelasticity. The advantage of the method is its simplicity, that is, no time history analysis is needed to be performed.

The main elements of the spectral capacity-based loss assessment methodology can be summarized as follows:

- Earthquake demand representation: demand spectrum

- Structural system representation: building capacity spectrum

- Structural response assessment: performance point

- Representation of the damage probability: fragility curves

\subsection{Representation of earthquake demand}

Following the estimation of the spatial distribution of selected ground motion parameters, i.e. peak ground acceleration (PGA) and/or spectral accelerations $\left(S_{\mathrm{a}}\right)$, by the Hazard 


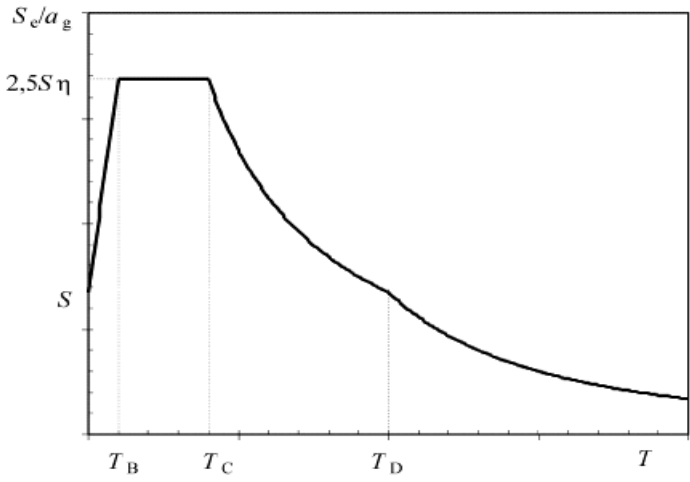

Fig. 4. Shape of the horizontal elastic response spectrum by EC8.

module, earthquake demand is represented by $5 \%$-damped elastic response spectrum. ELER provides two options for the construction of response spectral shape (Fig. 3):

1. EuroCode 8 (EC8) Spectrum

2. International Building Code (IBC 2006) Spectrum

\subsubsection{EuroCode 8 (EC8) Elastic Acceleration Spectrum}

EC8 suggests two types of elastic acceleration response spectra for horizontal components of the ground motion: Type 1 and Type 2. The shape of the elastic response spectrum is the same for the two levels of seismic action (Fig. 4).

If the earthquakes contributing most to the seismic hazard defined for the site for the purpose of probabilistic hazard assessment has a surface-wave magnitude, $M_{\mathrm{S}}$, not greater than 5.5 , it is recommended to adopt the Type 2 spectrum. The Type 1 spectrum is used for earthquakes with a magnitude greater than 5.5.

The horizontal elastic response spectrum is defined by:

$a_{\mathrm{g}}$ : design ground acceleration on type A ground

$T_{\mathrm{B}}, T_{\mathrm{C}}$ : the periods that limit the constant spectral acceleration region

$T_{\mathrm{D}}$ : the period that defines the beginning of the constant displacement range of the spectrum

$S:$ soil factor

$\eta$ : damping correction factor

The values of $T_{\mathrm{B}}, T_{\mathrm{C}}, T_{\mathrm{D}}$ and $S$ for each ground type and type (shape) of spectrum to be used as well as the damping corrections for different levels of damping are given by EC8 and are already implemented in ELER.

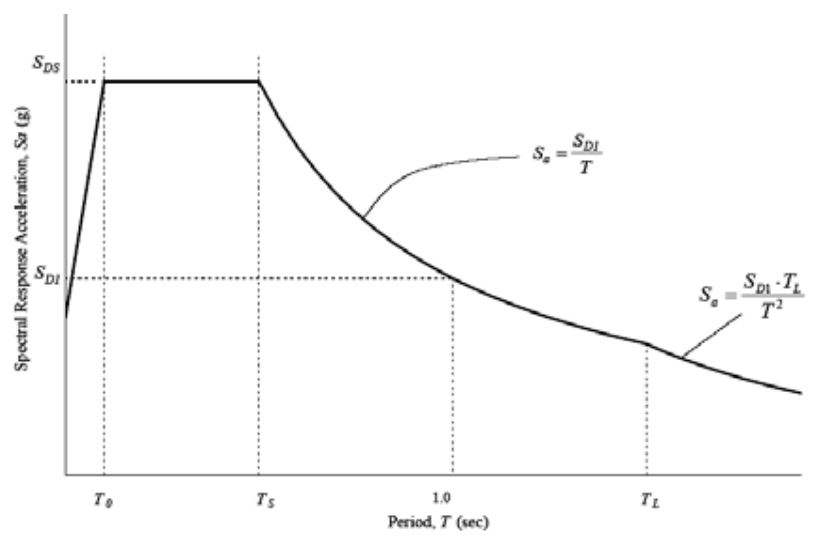

Fig. 5. Shape of the horizontal elastic response spectrum by IBC 2006.

\subsubsection{International Building Code (IBC 2006) elastic acceleration spectrum}

IBC 2006 provides a general horizontal elastic acceleration response spectrum as depicted in Fig. 5. The response spectral shape is defined by:

$S_{\mathrm{S}}, S_{1}$ : spectral accelerations at short period and $1 \mathrm{~s}$ period, respectively

$S_{\mathrm{DS}}, S_{\mathrm{D} 1}$ : short period and 1-s period design response spectral accelerations adjusted for the specified site class and damping value

$T_{0,}, T_{\mathrm{S}}$ : corner periods of the constant spectral acceleration region given by $T_{0}=0.2 T_{\mathrm{S}}$ and $T_{\mathrm{S}}=S_{\mathrm{D} 1} / S_{\mathrm{DS}}$

$T_{\mathrm{L}}$ : long-period transition period. It is a regionaldependent parameter and it is assumed that $T_{\mathrm{L}}=5 \mathrm{~s}$ in ELER.

The recommended values for the site and damping corrections are given in IBC 2006 and NEHRP 2003 Provisions. They have already been implemented in ELER.

\subsubsection{Seismic demand spectrum}

For utilization in capacity spectrum-based vulnerability analysis, the elastic 5\%-damped response spectrum (in spectral acceleration versus period format, $\left.S_{\mathrm{ae}}, T\right)$ is converted into the spectral acceleration $\left(S_{\mathrm{ae}}\right)$ versus spectral displacement $\left(S_{\mathrm{de}}\right)$, the so-called ADRS (acceleration-displacement response spectrum) format, through use of the following transformation:

$S_{\mathrm{de}}=\left(\frac{T^{2}}{4 \pi^{2}}\right) S_{\mathrm{ae}}$

Figure 6 illustrates standardized spectrum shape plotted in ADRS format. 


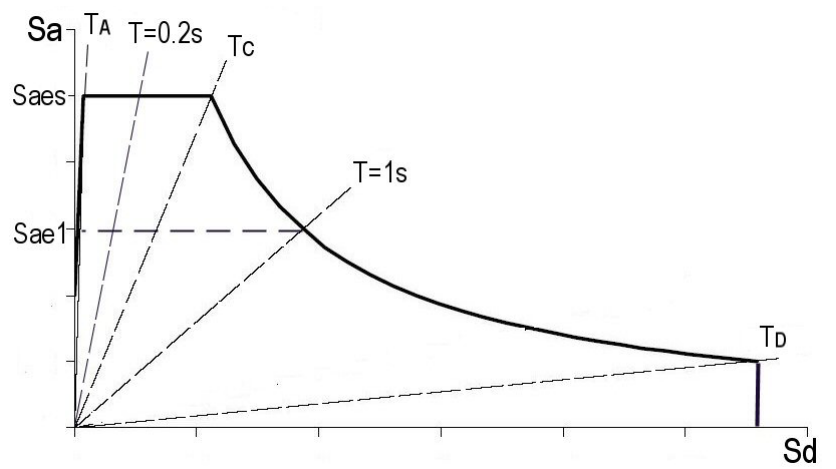

Fig. 6. Standardized seismic demand spectrum plotted in ADRS format $\left(T_{\mathrm{A}}, T_{\mathrm{C}}\right.$ and $T_{\mathrm{D}}$ show the characteristic periods. $S_{\text {aes }}$ and $S_{\text {ae1 }}$ respectively indicate the short period and $1 \mathrm{~s}$ period spectral (elastic) accelerations).

\subsection{Building damage assessment}

\subsubsection{Building inventory and classification}

A building inventory is a catalogue of buildings in each class of the assumed classification system. The definition of a classification system for the characterization of the exposed building stock and the description of its damage is an essential step in a risk analysis in order to ensure a uniform interpretation of data and results. For a general building stock, the following parameters affect the damage and loss characteristics: structural (system, height, and building practices), non-structural elements and occupancy (such as residential, commercial, and governmental).

HAZUS (1999) and RISK-UE building taxonomies are the classification systems envisaged in the development of ELER (Fig. 7). In fact, ELER is structured in such a way that a building inventory can be classified in terms of any classification system as long as the analytical vulnerability relations and capacity curves associated with each building type is defined by the user. The user has the capability of defining custom capacity and fragility curves by Building Database Creator tool. In HAZUS (1999) the general building inventory includes residential, commercial, industrial, agricultural, religious, governmental, and educational buildings. HAZUS (1999) envisages a classification by the height of the structure (three classes are distinguished depending on the number of floors), in addition to a further classification of each structural system by the design level (four code levels: High-Code, Moderate-Code, Low-Code, Pre-Code). An exception is made for Steel Frame with Unreinforced Masonry Infill Walls and Concrete Frame with Unreinforced Masonry Infill Walls for which Moderate Code is not considered and for Unreinforced Masonry Bearing Walls for which High Code is not present. A comprehensive building type classification for Europe that incorporated the characteristic features of the European building taxon-

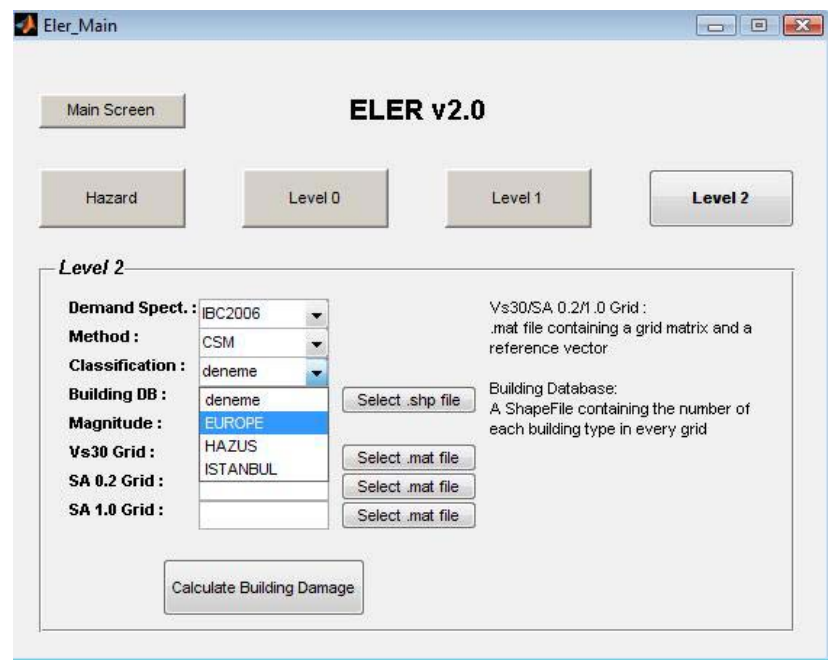

Fig. 7. Default building taxonomies provided by ELER: European building taxonomy, HAZUS model building classes and Istanbul building classes created by Building Database Creator tool.

omy, was developed in the European Commission- funded RISK-UE project (RISK-UE, 2001-2004) entitled "An Advanced Approach to Earthquake Risk Scenarios with Application to Different European Towns". The European building classification proposed in Giovinazzi (2005) based on RISKUE project is utilized in ELER. The classification includes a basic division, similar to HAZUS' classification, in terms of construction type and number of floors. Masonry building classes cover a wide range of masonry construction encountered in Europe, such as rubble stone, adobe, simple stone, massive stone, unreinforced masonry and reinforced masonry. Reinforced concrete buildings are grouped as nondesigned and code-designed buildings. Code-designed reinforced concrete buildings are further sub-divided in terms of the ductility of lateral load carrying systems, i.e. low, moderate and high ductility.

In ELER structure, the building inventory should be associated with geographical coordinates in order to perform a loss-estimation study resulting from the ground motion generated by a specific earthquake, or obtained from a hazard study.

\subsubsection{Representation of building capacity}

A building capacity curve is the plot of the building's lateral load resistance as a function of a characteristic lateral displacement and quantifies the inelastic structural capacity of the structure. Capacity spectrum can be approximated from a "pushover" analysis in which monotonically increasing lateral loads are applied to the structure and the characteristic deformations (usually roof level displacement) are plotted against the lateral load. The capacity spectrum-based vulnerability analysis requires that the pushover curve of 


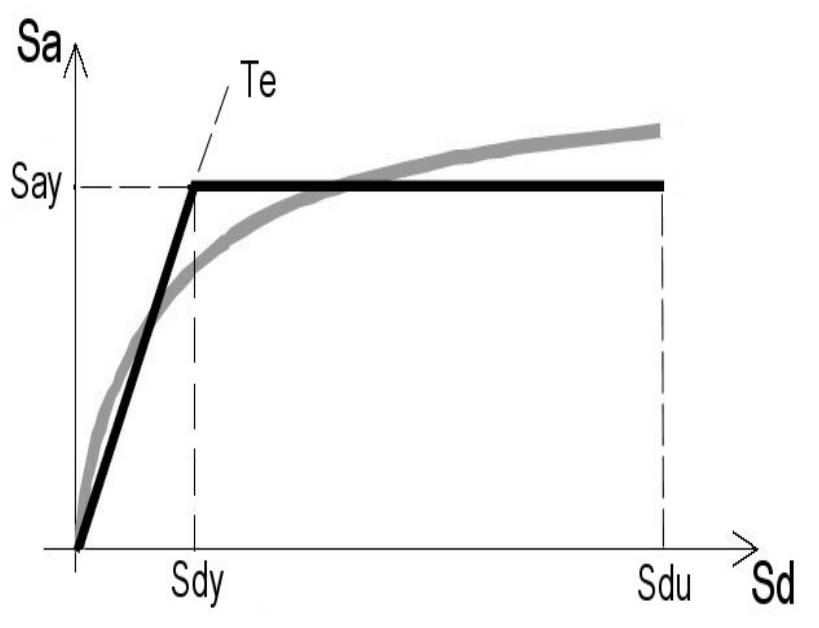

Fig. 8. Typical structural capacity spectrum and its simplified form (solid curve).

the MDOF system, quantified by the base shear $(V)$ and the top floor displacement $(D)$, be converted to the capacity spectrum of the equivalent single-degree-of-freedom (SDOF) system quantified by the spectral acceleration $\left(S_{\mathrm{a}}\right)$ and spectral displacement $\left(S_{\mathrm{d}}\right)$ for direct comparison with the associated demand spectrum.

For each building type the capacity spectrum has an initial linear section where the slope depends on the typical natural frequency of vibration of the building class, and rises to a plateau level of spectral acceleration at which the maximum attainable resistance to static lateral force has been reached. As an example, a capacity spectrum is shown in Fig. 8. As can be seen, the capacity spectrum is controlled by the points of design, yield and ultimate capacities. These points can be correlated with the damage limit states.

For the building taxonomies, RISK-UE building typologies and model building types of HAZUS'99, the capacity curve parameters as described above are provided in the ELER database.

\subsection{Calculation of performance point}

Nonlinear Static Procedures are widely used to estimate the performance point (target displacement). The commonly used ones are: the Capacity Spectrum Method specified in ATC-40 (1996), its recently modified and improved version Modified Acceleration-Displacement Response Spectrum Method (FEMA-440) and the Coefficient Method originally incorporated in FEMA-356 (2000).

The Capacity Spectrum Method is a form of equivalent linearization that uses empirically derived relationships for the effective period and damping to estimate the response of an equivalent linear SDOF model. The Modified AccelerationDisplacement Response Spectrum Method differs basically from the Capacity Spectrum Method in the reduction of the elastic demand curve. The basic assumption of the equivalent linearization is that the maximum displacement of a nonlinear SDOF system can be estimated from the maximum displacement of a linear elastic SDOF system having a period and a damping ratio larger than those of the initial values for the nonlinear system. The elastic SDOF system used to estimate the maximum inelastic displacement of the nonlinear system is usually referred to as the equivalent or substitute system. Similarly, the period of vibration and damping ratio of the elastic system are commonly referred to as equivalent period and equivalent damping ratio, respectively. The equivalent period is computed from the initial period of vibration of the nonlinear system and from the maximum displacement ductility ratio, $\mu$. On the other hand, the equivalent damping ratio is computed as a function of damping ratio in the nonlinear system and the displacement ductility ratio.

The Coefficient Method is essentially a spectral displacement modification procedure in which several empirically derived factors are used to modify the response of a linearlyelastic equivalent SDOF model of the building structure.

Another nonlinear static procedure is the so-called "N2" method (Fajfar, 2000) in which the inelastic demand spectra is obtained from standardized (code-based) elastic design spectra using ductility factor-based reduction factors. The "N2" method (herein called the Reduction Factor Method) has been implemented in the so-called "Mechanical-Based Method" of vulnerability analysis (Lagomarsino and Giovinazzi, 2006) in the RISK-UE (2001-2004) project.

All four of these methodologies require development of a pushover curve (capacity spectrum for the equivalent SDOF system) to provide the relationship between the base shear and lateral displacement of a control node (usually located at roof level). They differ mainly in the computation of the demand spectrum and the performance point. Calculation of the performance point by each method is explained in the forthcoming sections.

\subsubsection{Capacity Spectrum Method - CSM}

The Capacity Spectrum Method (CSM) utilizes the equivalent linearization for the estimation of the performance point, which is the intersection of the building capacity spectrum with the demand response spectrum reduced for nonlinear effects. The performance point represents the condition for which the seismic capacity of the structure is equal to the seismic demand imposed on the structure by the given level of ground shaking (ATC-40).

To account for the increased hysteretic damping as the building shifts from elastic into inelastic response, the spectral reduction factors in terms of effective damping are introduced. The effective damping (essentially the equivalent damping, $\beta_{\text {eq }}$ ) can be calculated as a function of the capacity curve, the estimated displacement demand and the resulting hysteresis loop. For more realistic approximation of the 


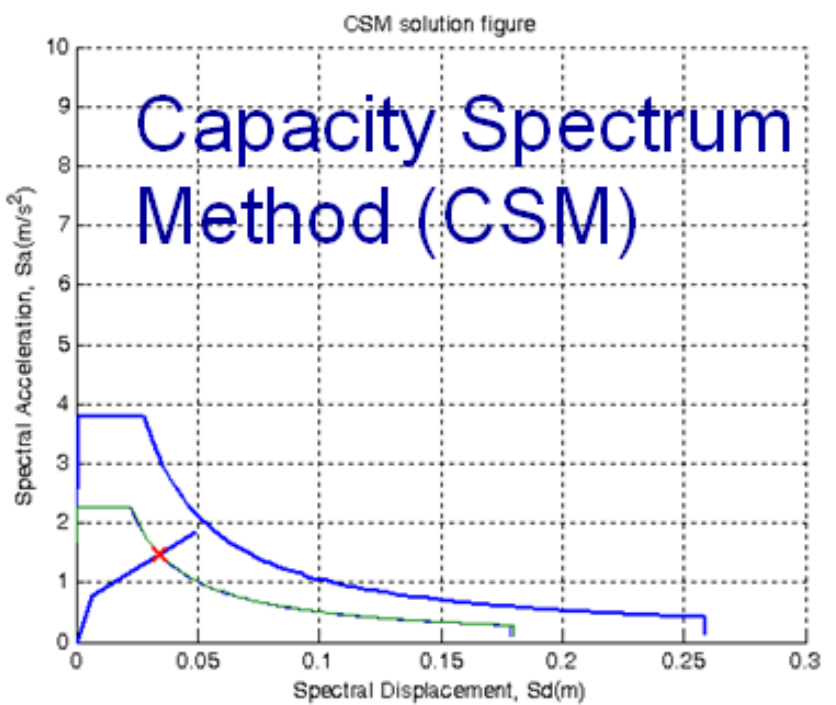

Fig. 9. MATLAB solution representation for CSM.

hysteretic energy dissipated by the structure, the effective viscous damping $\left(\beta_{\text {eff }}\right)$ concept is utilized with the consideration of a damping modification factor $(\kappa)$. The effective damping is defined by ATC-40 as:

$\beta_{\text {eff }}=\kappa \beta_{0}+5=\frac{63.7 \kappa\left(a_{\mathrm{y}} d_{\mathrm{pi}}-d_{\mathrm{y}} a_{\mathrm{pi}}\right)}{a_{\mathrm{pi}} d_{\mathrm{pi}}}+5$

where $\beta_{0}$ is the hysteretic damping and " 5 " stands for the $5 \%$ viscous damping inherent in the structure (assumed to be constant).

The $\kappa$-factor is related to the structural behaviour and the earthquake duration. ATC-40 provides three categories of structural behaviour: Type A - stable, reasonably full hysteresis loops, Type B - moderately reduced hysteretic behaviour and Type $\mathrm{C}$ - poor hysteretic behaviour. Based on the evaluation of the building's seismic resisting system and the earthquake duration, the structural behaviour types and the variation of $\kappa$ values are provided in tabular forms in ATC-40.

To obtain the reduced demand spectrum ATC-40 applies the following spectral reduction factors:

$\mathrm{SR}_{\mathrm{A}}=\frac{3.21-0.68 \ln \left(\beta_{\mathrm{eff}}\right)}{2.12}$

$\mathrm{SR}_{\mathrm{V}}=\frac{2.31-0.41 \ln \left(\beta_{\mathrm{eff}}\right)}{1.65}$

$\mathrm{SR}_{\mathrm{A}}$ and $\mathrm{SR}_{\mathrm{V}}$ are, respectively, applied to the constant acceleration and the constant velocity regions of the 5\%-damped elastic demand spectrum.

For the determination of the performance point, two criteria need to be satisfied: (1) the point must lie on the capacity spectrum to represent the structure at a given displacement and (2) the point must lie on a reduced demand spectrum that

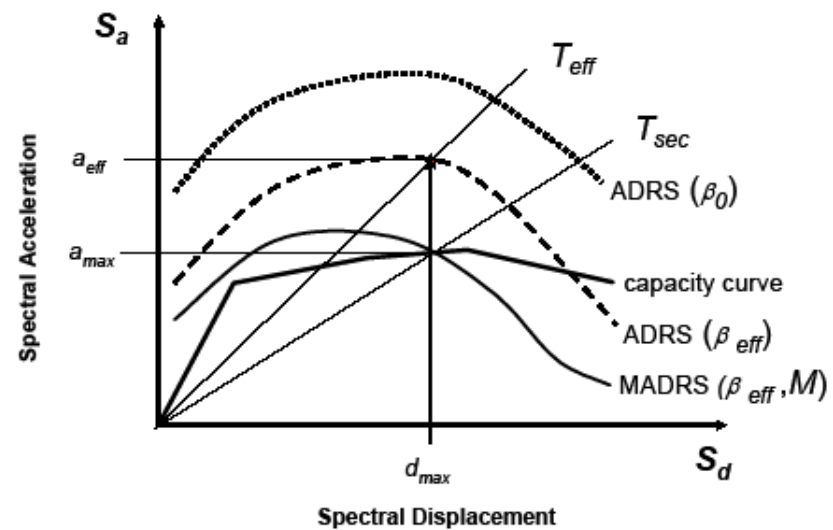

Fig. 10. Modified acceleration-displacement response spectrum (MADRS) for use with secant period (taken from FEMA-440).

represents the nonlinear demand at the same structural displacement. In order to achieve this, three iterative procedures based on trial and error search are suggested in ATC-40. The so-called Procedure A is utilized in the implementation of the CSM herein. In Procedure A, a trial performance point $\left(a_{\mathrm{pi}}, d_{\mathrm{pi}}\right)$, is selected; then the bilinear capacity spectrum and the reduced demand spectrum are drawn on the same plot. It is then determined whether the demand spectrum intersects the capacity spectrum at the point $\left(a_{\mathrm{pi}}, d_{\mathrm{pi}}\right)$ or if the displacement at which the demand spectrum intersects the capacity spectrum, $d_{i}$, is within acceptable tolerance of $d_{\mathrm{pi}}$.

Figure 9 illustrates the determination of the performance point based on the Procedure A by Level 2 module.

\subsubsection{Modified Acceleration-Displacement Response Spectrum Method - MADRS}

The CSM rests on the idea of reducing the elastic acceleration spectrum with an equivalent viscous damping of a linear single-degree-of-freedom (SDOF) system represented by its secant stiffness at maximum displacement. There has been a debate on whether the empirically defined spectrum reduction factors are representative of the inelastic behaviour of the equivalent SDOF system since the inception of the method. The method has been improved in FEMA-440 (2005) through the introduction of the so-called Modified Acceleration-Displacement Response Spectrum (MADRS) method. The MADRS method estimates the maximum displacement response of the nonlinear system with an equivalent linear system using the effective period $\left(T_{\text {eff }}\right)$ and effective damping $\left(\beta_{\text {eff }}\right)$.the effective linear parameters are functions of the capacity spectrum, the corresponding initial period and damping, and the ductility demand $(\mu)$.

The use of effective period and damping generates a maximum displacement that coincides with the intersection of the radial effective period line and the ADRS demand. The intersection point is presented by the $a_{\max }$ and $d_{\max }$ (Fig. 10). 


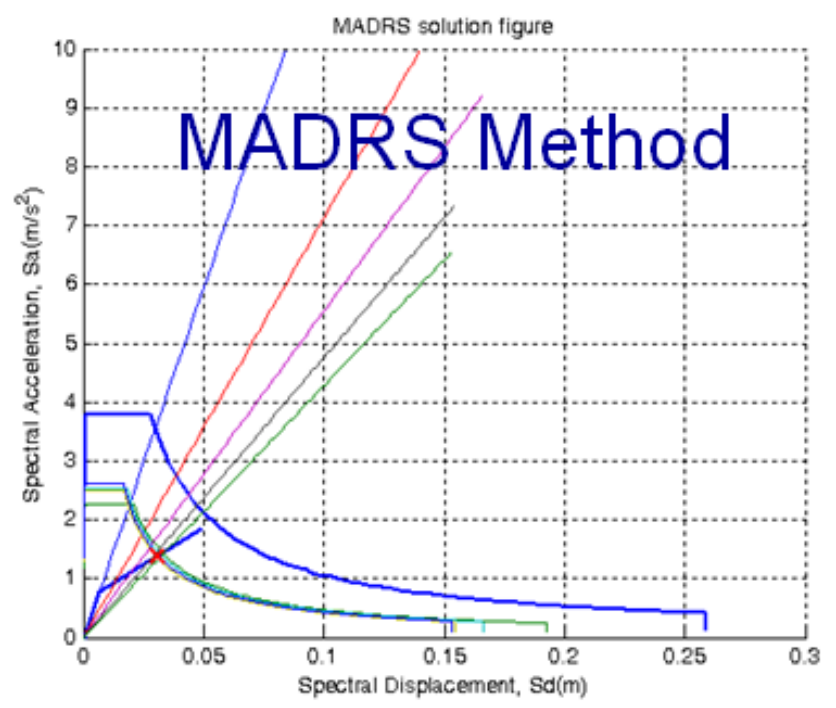

Fig. 11. MATLAB solution representation for MADRS.

The modified ADRS demand curve (MADRS) is obtained by multiplying the values of the ADRS demand corresponding to the effective damping, $\beta_{\text {eff }}$, by the modification factor $M$, as given in FEMA-440 document:

$M=\frac{a_{\mathrm{max}}}{a_{\mathrm{eff}}}=\left(\frac{T_{\mathrm{eff}}}{T_{\mathrm{s}}}\right)^{2}=\left(\frac{T_{\mathrm{eff}}}{T_{0}}\right)^{2}\left(\frac{T_{0}}{T_{\mathrm{s}}}\right)^{2}$

where

$$
\left(\frac{T_{0}}{T_{\mathrm{S}}}\right)^{2}=\frac{1+\alpha(\mu-1)}{\mu}
$$

$\alpha$ is the post-elastic stiffness and $\mu$ is the ductility demand and given by:

$$
\alpha=\frac{\left(\frac{a_{\mathrm{pi}}-a_{\mathrm{y}}}{d_{\mathrm{pi}}-d_{\mathrm{y}}}\right)}{\frac{a_{\mathrm{y}}}{d_{\mathrm{y}}}}
$$

$\mu=\frac{d_{\mathrm{pi}}}{d_{\mathrm{y}}}$

Similar to the CSM, spectral reduction factors are applied to obtain reduced demand spectra for the appropriate level of effective damping, $\beta_{\text {eff. }}$ In the MADRS method, these factors are termed damping coefficients, $B\left(\beta_{\text {eff }}\right)$, and used to adjust spectral acceleration ordinates given as follow:

$$
\left(S_{\mathrm{a}}\right)_{\beta}=\frac{\left(S_{\mathrm{a}}\right)_{0}}{B\left(\beta_{\mathrm{eff}}\right)}
$$

$$
B=\frac{4}{5.6-\ln \beta_{\text {eff }}(\text { in } \%)}
$$

FEMA-440 considers three different types of inelastic behaviour which are used as the equivalent counterparts to simulate the maximum response of an actual inelastic system:
BLH - bilinear hysteretic, STDG - stiffness degrading and STRDG - strength degrading model. For the implementation of the equivalent linearization in the MADRS method, the user has the choice of one of the hysteretic models or the approximate equations for the calculation of equivalent linear parameters, the effective damping $\left(\beta_{\text {eff }}\right)$ and effective period $\left(T_{\text {eff }}\right)$. However, FEMA-440 indicates that the results are an estimate of median response and imply no factor of safety for structures that may exhibit poor performance and/or large uncertainty in behaviour. The effective parameters for equivalent linearization are functions of ductility. Since ductility (the ratio of maximum displacement to yield displacement) is the object of the analysis, the solution must be found using iterative or graphical techniques. FEMA-440 suggests three procedures for the determination of the performance point although it should be noted that these procedures may not be reliable for extremely high ductilities (e.g., greater than 10 to 12). The so-called Procedure $\mathrm{C}$ is utilized in the implementation of the MADRS method herein since its iterative procedure takes relatively lesser time. It uses the modified acceleration-response spectrum for multiple assumed solutions $\left(a_{\mathrm{pi}}, d_{\mathrm{pi}}\right)$ and the corresponding ductilities to generate a locus of possible performance points. The actual performance point is located at the intersection of this locus and the capacity spectrum (Fig. 11).

\subsubsection{Reduction Factor Method - RFM}

The Reduction Factor Method (RFM) utilizes the constantductility inelastic response spectra obtained through application of a reduction factor $R_{\mu}$ to the elastic response spectra in order to account the inelastic behaviour (Fajfar, 2000).

For an inelastic single-degree-of-freedom system with a bi-linear force-deformation relationship, the inelastic spectral acceleration $\left(S_{\mathrm{ai}}\right)$ and the inelastic spectral displacement $\left(S_{\mathrm{di}}\right)$ can be determined as:

$S_{\mathrm{ai}}=S_{\mathrm{ae}} / R_{\mu}$

$S_{\mathrm{di}}=\frac{\mu}{R_{\mu}} S_{\mathrm{de}}=\frac{\mu}{R_{\mu}} \frac{T^{2}}{4 \pi^{2}} S_{\mathrm{ae}}=\mu \frac{T^{2}}{4 \pi^{2}} S_{\mathrm{ai}}$

where $\mu$ is the ductility factor defined as the ratio between maximum displacement and yield displacement and $R_{\mu}$ is the reduction factor (Fig. 12) given by:

for $T_{\mathrm{e}}<T_{\mathrm{C}}, R_{\mu}=(\mu-1) \frac{T_{\mathrm{e}}}{T_{\mathrm{C}}}+1$ and $S_{\mathrm{di}}=\frac{\mu}{R_{\mu}} S_{\mathrm{de}}$

for $T_{\mathrm{e}} \geq T_{\mathrm{C}}, R_{\mu}=\mu \quad$ and $\quad S_{\mathrm{di}}=S_{\mathrm{de}}$

where $T_{\mathrm{e}}$ is the elastic period of the SDOF system and $T_{\mathrm{C}}$ is the characteristic period of the ground motion.

The performance point $S_{\mathrm{dp}}$ (in terms of the spectral displacement) can be defined as functions of the structural capacity curve ( $T_{\mathrm{e}}, S_{\text {ay }}$ and $\left.\mu\right)$ and seismic demand curve ( $S_{\mathrm{ae}}$, $\left.T_{\mathrm{C}}, T_{\mathrm{D}}, \mu\right)$. 

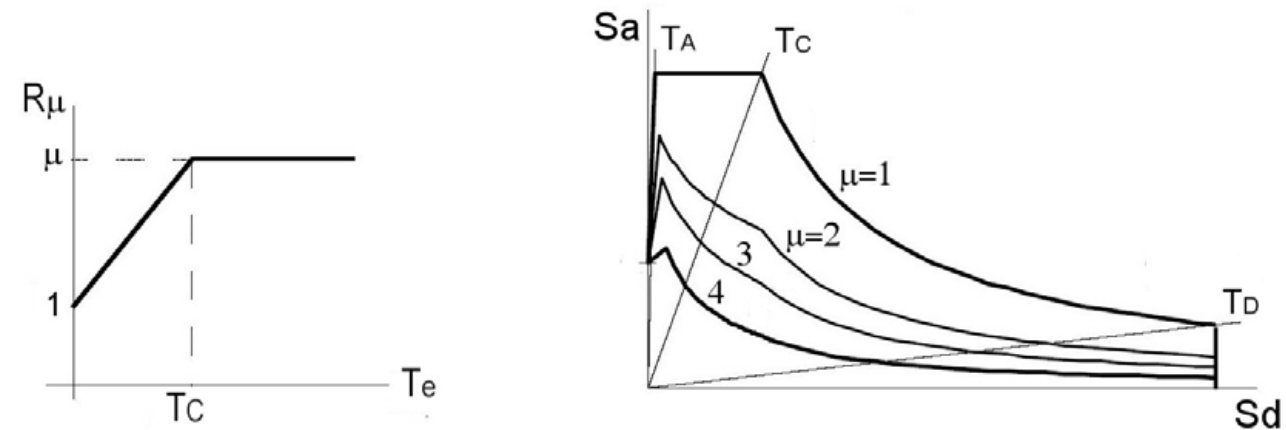

Fig. 12. Reduction factor and the demand spectrum (modified after Fajfar, 2000).

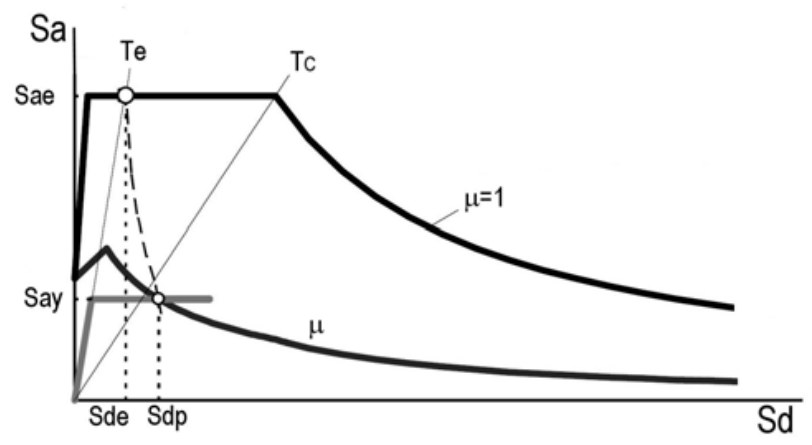

Fig. 13. Performance point for $T_{\mathrm{e}}<T_{\mathrm{C}}$ (Modified after Fajfar, 2000).

For cases where the elastic period $T_{\mathrm{e}}$ is less than $T_{\mathrm{C}}$ and $S_{\mathrm{ae}}>S_{\text {ay }}$ (Fig. 13), through the use of Eqs. (14) and (15) the performance point can be given as:

$S_{\mathrm{dp}}=\mu S_{\mathrm{dy}}=\frac{S_{\mathrm{de}}\left(T_{\mathrm{e}}\right)}{R_{\mu}}\left(1+\left(R_{\mu}-1\right) \frac{T_{\mathrm{c}}}{T_{\mathrm{e}}}\right)$

where

$R_{\mu}=(\mu-1) \frac{T_{\mathrm{e}}}{T_{\mathrm{C}}}+1$ and $\mu=\left(R_{\mu}-1\right) \frac{T_{\mathrm{C}}}{T_{\mathrm{e}}}+1$

Using Eq. (16) and from Fig. 14, it can be assessed that for cases where $T_{\mathrm{e}}$ is between $T_{\mathrm{C}}$ and $T_{\mathrm{D}}$ and $S_{\mathrm{ae}}>\mathrm{S}_{\mathrm{ay}}$ the performance point is equal to the elastic spectral demand.

$S_{\mathrm{dp}}=S_{\mathrm{de}}\left(T_{\mathrm{e}}\right)$

$R_{\mu}=\frac{S_{\mathrm{ae}}\left(T_{\mathrm{e}}\right)}{S_{\mathrm{ay}}}=\mu$

For cases where $T_{\mathrm{e}}$ is greater that $T_{\mathrm{D}}$ and $S_{\mathrm{ae}}>S_{\text {ay }}$ the performance point will be equal to the constant elastic spectral displacement level and can be given as:

$S_{\mathrm{dp}}=S_{\mathrm{de}}\left(T_{\mathrm{D}}\right)=\frac{S_{\mathrm{ae}}\left(T_{\mathrm{D}}\right) T_{\mathrm{D}}^{2}}{4 \pi^{2}}$

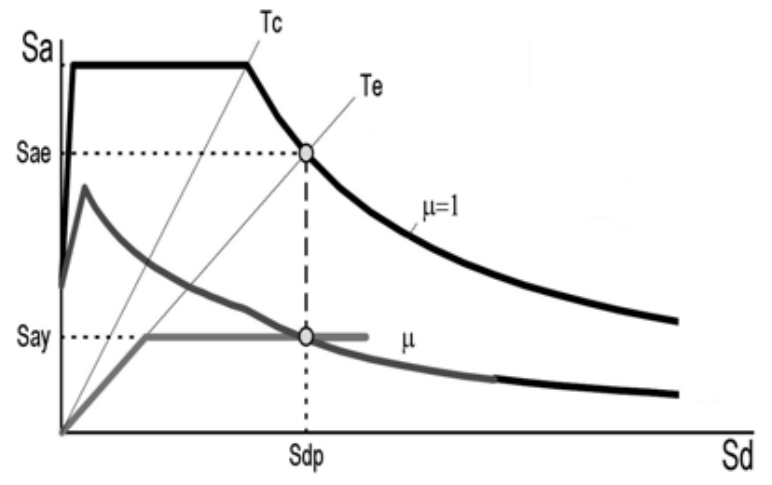

Fig. 14. Performance point for $T_{\mathrm{e}} \geq T_{\mathrm{C}}$ (Modified after Fajfar, 2000).

where $T_{\mathrm{D}}$ is the period that defines the beginning of the constant spectral displacement range.

For $S_{\text {ay }}>S_{\text {ae }}$ and for all positions of $T_{\mathrm{e}}$ (with respect to $T_{\mathrm{C}}$ and $T_{\mathrm{D}}$ ) the performance point can be given as:

$S_{\mathrm{dp}}=S_{\mathrm{de}}\left(T_{\mathrm{e}}\right)$

The Reduction Factor Method has been utilized by Lagomarsino and Giovinazzi (2006) in the derivation of the fragility and capacity curves for the RISK-UE building typologies. Those fragility and capacity curve parameters are proposed for the European building taxonomy in the ELER database.

\subsubsection{Coefficient Method - CM}

The Coefficient Method (CM), presented as a nonlinear static analysis procedure in FEMA-356 (2000) and FEMA273 (1997) essentially modifies the linear elastic response of the equivalent SDOF system by multiplying it by a series coefficients to generate an estimate of the target displacement (performance point). The coefficient method has been critically evaluated in FEMA-440 (2005) and the results reflected in ASCE/SEI 41-06 (2007). 


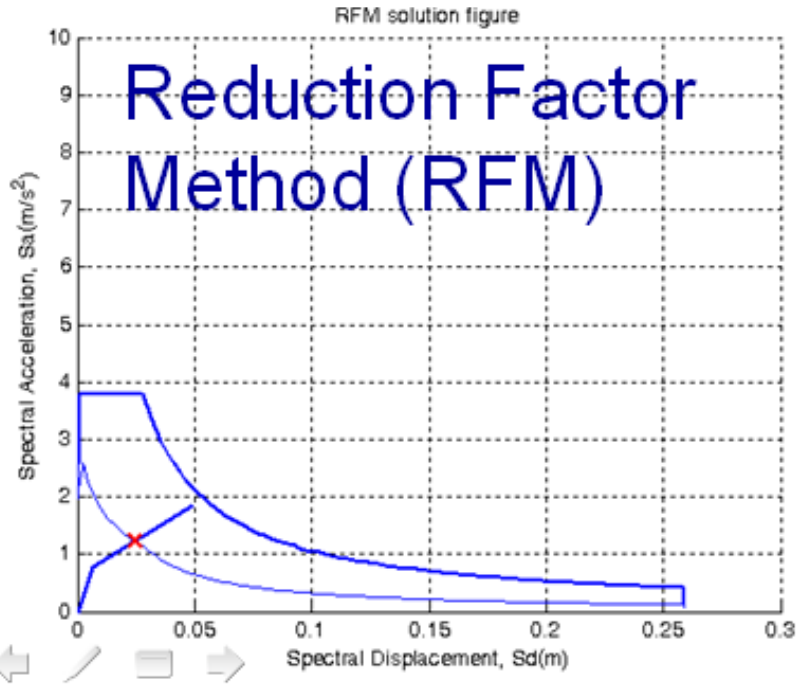

Fig. 15. MATLAB solution representation for RFM.

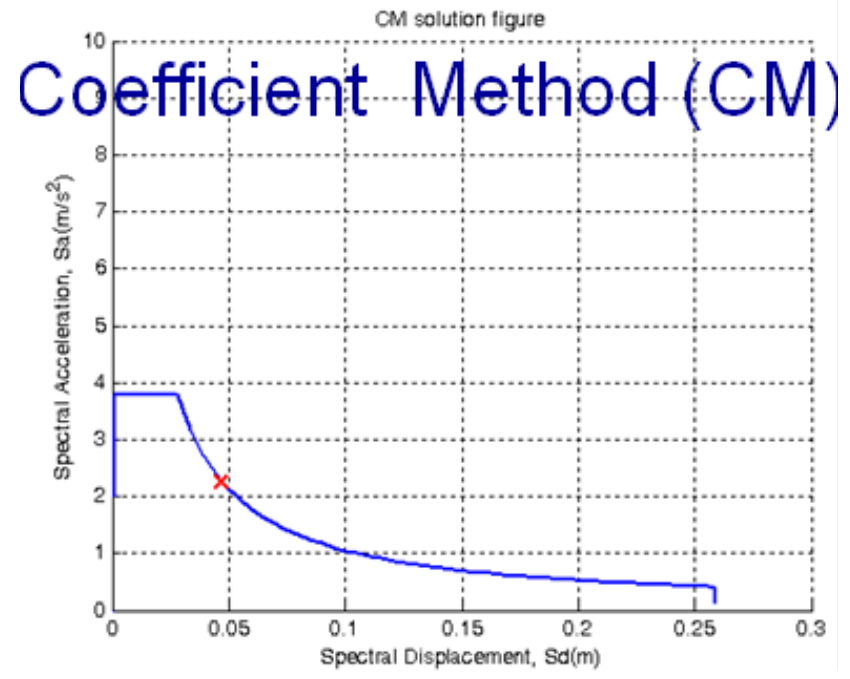

Fig. 16. MATLAB solution representation for CM.

Using this method, the inelastic spectral displacement demand (the performance point, $S_{\mathrm{dp}}$ ) is obtained through multiplying the elastic spectral displacement $\left(S_{\mathrm{de}}\right)$ by the $C_{0}, C_{1}$ and $C_{2}$ coefficients.

$\mathrm{S}_{\mathrm{d}} \mathrm{p}=C_{0} C_{1} C_{2} S_{\mathrm{de}}$

The elastic spectral displacement is computed at the fundamental period $\left(T_{\mathrm{e}}\right)$ of the equivalent SDOF system.

$C_{0}$ is the modification factor that relates the spectral displacement of the equivalent SDOF system to the roof displacement of the building's MDOF structural system. $C_{0}$ is equal to the first mode participation factor at the roof level $\left(C_{0}=\Gamma\right.$ of Eq. (48) if the amplitude of the mode at the roof level is set to unity). Table 3.2 of ASCE/SEI 41-06 (2007) provides tabulated values of $C_{0}$ for general building types.
Table 1. Values for the $\mathrm{C}_{0}$ coefficient with respect to number of stories.

\begin{tabular}{cc}
\hline $\mathrm{C}_{0}$ & $\begin{array}{c}\text { Number } \\
\text { of stories }\end{array}$ \\
\hline 1 & 1 \\
1.2 & 2 \\
1.3 & 3 \\
1.4 & 5 \\
1.5 & $>0$ \\
\hline
\end{tabular}

Table 2. Values for the factor a with respect to NEHRP site classification.

\begin{tabular}{ll}
\hline NEHRP Site Class & $\mathrm{a}$ \\
\hline A and B & 130 \\
C & 90 \\
D, E and F & 60 \\
\hline
\end{tabular}

$C_{0}$ increases with number of floors and varies between 1 and 1.5 (Table 1).

The $C_{1}$ coefficient, defined as the modification factor to relate expected maximum inelastic displacements to displacements calculated for linear elastic response, is given by (ASCE/SEI 41-06, 2007):

$C_{1}=1+\left(R_{\mathrm{y}}-1\right) /\left(a T_{\mathrm{eff}}^{2}\right)$

for $T_{\text {eff }} \leq 0.2 \mathrm{~s}, C_{1} \leq C_{1}\left(T_{\text {eff }}=0.2 \mathrm{~s}\right)$

for $T_{\text {eff }} \geq 1 \mathrm{~s}, C_{1}=1.0$

where $T_{\text {eff }}$ is the effective fundamental period of the building computed by modifying the fundamental mode vibration period ( $T_{\mathrm{e}}$, obtained from linearly elastic dynamic analysis) by:

$T_{\text {eff }}=T_{\text {e }} \sqrt{\frac{K_{i}}{K_{\text {eff }}}}$

where $K_{i}$ is the elastic stiffness of the building and $K_{\text {eff }}$ is the effective stiffness of the building obtained by idealizing the pushover curve as a bilinear relationship. In the application of Coefficient Method herein, it is assumed that $T_{\text {eff }}$ is equal to $T_{\mathrm{e}}$.

$R_{\mathrm{y}}$ represents the ratio of elastic strength demand to yield strength:

$R_{\mathrm{y}}=\frac{S_{\mathrm{ae}}\left(T_{\mathrm{eff}}\right)}{S_{\mathrm{ay}}}$

where $S_{\text {ae }}\left(T_{\text {eff }}\right)$ represents the elastic spectral acceleration at the effective fundamental period of the structure and $S_{\text {ay }}$ refers to the yield spectral acceleration. 
The factor "a" in Eq. (22) is called the site class factor as given in Table 2:

The $C_{2}$ coefficient represents the modification factor for the effect of pinched hysteresis shape, cyclic stiffness degradation and strength deterioration (ASCE/SEI 41-06, 2007):

$C_{2}=1+\frac{1}{800}\left(\frac{R_{\mathrm{y}}-1}{T_{\mathrm{eff}}}\right)^{2}$

for $T_{\text {eff }} \geq 0.7 \mathrm{~s}, C_{2}=1.0$

When comparing the Coefficient Method with the other three methods of Level 2 analysis, the user might expect differences to some degree in damage estimations. Whereas the first three methods rely on more complicated procedures, e.g. equivalent linearization, reduction of the demand spectra and the iterative procedures for estimating the performance point, the Coefficient Method modifies the elastic spectral displacement by multiplying some coefficients to obtain the performance point.

\subsection{Fragility functions and calculation of damage probability}

The conditional probability of damage being in or exceeding a particular damage state $k$ (or $D_{k}$ ) for a given spectral displacement level (performance point, $S_{\mathrm{dp}}$ ) is given by the following relationship:

$$
P\left[\text { Damage } \geq D_{k} \mid S_{\mathrm{dp}}\right]=\Phi\left[\left(1 / \beta_{k}\right) \ln \left(S_{\mathrm{dp}} / \bar{S}_{d, k}\right)\right]
$$

where $\Phi$ is the standard normal (Gaussian) complementary cumulative function, $S_{\mathrm{dp}}$ is the inelastic spectral displacement demand (performance point), $\bar{S}_{d, k}$ is the median spectral displacement at which the structure reaches the threshold of the damage state $(k)$ and $\beta_{k}$ is the standard deviation of the natural logarithm of the $S_{d, k}$.

The spectral displacement $S_{d, k}$ that defines the threshold of a particular damage state $(k)$ is assumed to be given by:

$S_{d, k}=\bar{S}_{d, k} \varepsilon_{k}$

where $\bar{S}_{d, k}$ is the median value and $\varepsilon_{k}$ is the log-normal variable with a unit median value and a normalized composite log-normal standard deviation $\beta_{k}$, that incorporates aspects of uncertainty and randomness for both capacity and demand.

The application of the spectral capacity-based vulnerability assessment requires the provision of $\bar{S}_{d, k}$ and $\beta_{k}$ values for different model building types and the damage states are needed for the assessment of damage predictions to buildings, casualties and socio-economic losses due to structural damage. Slight, Moderate, Extensive and Complete damage states for each building model types of HAZUS (1999) as well as for the European building taxonomy are adopted in the Level 2 analysis.

\subsubsection{Building damage state probability}

HAZUS (1999) and Kircher et al. (1997) provide the median values of the threshold spectral displacements $\left(\bar{S}_{d, k}\right)$ at the damage state $k$ as:

$\bar{S}_{d, k}=\delta_{k} \alpha_{2} H$

where, $\delta_{k}$ is the drift ratio at the threshold of the damage state $k, \alpha_{2}$ is the fraction of the building (roof) height at the location of the pushover mode displacement and $H$ is the typical roof level height of the building type considered. HAZUSMH (2003) provides $\alpha_{2}$ and $H$ values for different building types. The $\delta_{k}$ and values are provided as a function of the seismic design level and damage state for different building types.

For the European building taxonomy, Lagomarsino and Giovinazzi (2006) identify the following damage limit states (damage state thresholds) on the capacity curve:

$$
\begin{aligned}
& \bar{S}_{d, 1}=0.7 S_{\mathrm{dy}} \\
& \bar{S}_{d, 2}=1.5 S_{\mathrm{dy}} \\
& \bar{S}_{d, 3}=0.5\left(S_{\mathrm{dy}}+S_{\mathrm{du}}\right) \\
& \bar{S}_{d, 4}=S_{\mathrm{du}}
\end{aligned}
$$

where $\overline{\mathrm{S}}_{d, k}(k=1,2,3,4)$ identify the median value of the damage state threshold spectral displacements. Four damage levels $\left(\mathrm{D}_{k}, k=1,2,3,4\right)$ are associated with these damage limit states: Slight- $\mathrm{D}_{1}$ (Slight in EMS98), Moderate- $\mathrm{D}_{2}$ (Moderate in EMS98), Extensive- $\mathrm{D}_{3}$ (Heavy in EMS98) and Complete- $\mathrm{D}_{4}$ (Very heavy + Destruction in EMS98).

The log-normal standard deviation $\beta_{k}$ which describes the total variability of the fragility curve damage states, has been modelled (Kircher et al., 1997) by the variability of the capacity curve $\left(\beta_{\mathrm{C}}\right)$, demand spectrum $\left(\beta_{\mathrm{D}}\right)$ and of the damage state threshold $\left(\beta_{T, k}\right)$. Each of these variabilities is represented by the log-normal standard deviation parameter.

$\beta_{k}=\sqrt{\left(\operatorname{CONV}\left[\beta_{\mathrm{C}}, \beta_{\mathrm{D}}\right]\right)^{2}+\left(\beta_{T, k}\right)^{2}}$

where "CONV" represents the convolution of respective probability distributions. The following general values are provided in HAZUS (1999):

$\beta_{\mathrm{C}}=0.25$ (for code buildings and $\beta_{\mathrm{C}}=0.30$ for pre-code buildings)

$\beta_{\mathrm{D}}=0.45$ (at short periods and $\beta_{\mathrm{D}}=0.50$ at long periods)

$\beta_{T, k}=0.4$ (for all building types and damage states)

HAZUS-MH (2003) provides tables of $\beta_{k}$ for low-, midand high-rise with different $\kappa, \beta_{T, k}$ and $\beta_{\mathrm{C}}$ ranges.

For the European building taxonomy, Lagomarsino and Giovinazzi (2006) express the total variability, $\beta_{k}$, as:

$\beta_{k}=\sqrt{\beta_{\mathrm{C}}^{2}+\beta_{\mathrm{D}}^{2}+\beta_{T, k}^{2}}$ 
Table 3. Description of injury severity levels.

\begin{tabular}{ll}
\hline Injury severity & Injury description \\
\hline Level 1 & $\begin{array}{l}\text { Injuries requiring basic medical aid } \\
\text { without requiring hospitalization }\end{array}$ \\
Level 2 & $\begin{array}{l}\text { Injuries requiring medical care and hospitalization, } \\
\text { but not expected to progress into a life threatening status }\end{array}$ \\
Level 3 & $\begin{array}{l}\text { Injuries that pose an immediate life threatening condition } \\
\text { if not treated adequately and expeditiously. The majority of } \\
\text { these injuries result because of structural collapse and } \\
\text { subsequent collapse or impairment of the occupants. } \\
\text { Instant death or mortal injured }\end{array}$ \\
\hline
\end{tabular}

Table 4. Casualty rates for reinforced concrete moment frame structures (HAZUS99).

\begin{tabular}{lllll}
\hline \multirow{2}{*}{ Injury severity } & \multicolumn{3}{c}{ Casualty rates for reinforced concrete structures (\%) } \\
\cline { 2 - 5 } & Slight damage & Moderate damage & Extensive damage & Complete damage \\
\hline Severity 1 & 0.05 & 0.2 & 1 & $5^{*}-50^{* *}$ \\
Severity 2 & 0.005 & 0.02 & 0.1 & $1^{*}-10^{* *}$ \\
Severity 3 & 0 & 0 & 0.001 & $0.01^{*}-2^{* *}$ \\
Severity 4 & 0 & 0 & 0.001 & $0.01^{*}-2^{* *}$ \\
\hline
\end{tabular}

\footnotetext{
* the smaller values are related to partial collapse of the buildings

** the larger values are given for total collapse (the pancake type of collapse)
}

Lagomarsino and Giovinazzi (2006) and Giovinazzi (2005) have evaluated $\beta_{k}$ by using binomial and log-normal distributions with a $50 \%$ probability of occurrence for each damage state as:

$\beta_{k}=0.40 \ln \mu$

and by forcing the log-normal fragility curves on beta fragility curves stated as:

$\beta_{k}=0.62 \ln \mu$

where $\mu$ is the ductility factor.

The log-normal standard variation given by Eq. (39) is adopted for the fragility functions of European building taxonomy.

\subsubsection{Fragility curves}

To estimate the performance of a group of buildings of a particular class under a given ground shaking, the spectral response of the building at the performance point for the standard building of that class, as defined above, is used in conjunction with a set of fragility curves for that class, which estimate the probability of any particular building exceeding each of the damage states after shaking at any given spectral response level.
The fragility curves represent the probability-based relation between the expected response and the performance limits in terms of the cumulative density function of the probability of exceeding the specific damage limit states for a given peak value of a seismic demand. If structural capacity and seismic demand are random variables that roughly conform to either a normal or log-normal distribution, then following the central limit theorem, it can be shown that the composite performance outcome will be log-normally distributed. Therefore, the probabilistic distribution is expressed in the form of a so-called fragility curve given by a log-normal cumulative probability density function.

The analytical expression of each fragility curve is based on the assumption that earthquake damage distribution can be represented by the cumulative standard log-normal distribution function, $\Phi$, (HAZUS, 1999 and Kircher et al., 1997). The horizontal axis represents the spectral displacement demand and the vertical axis refers to the cumulative probability of structural damage reaching or exceeding the threshold of a given damage state (Fig. 17).

For the building taxonomies, i.e. model building types of HAZUS and RISK-UE building typologies, the fragility curve parameters as described above are provided in the ELER database. 
Table 5. Casualty rates for unreinforced masonry structures (HAZUS99).

\begin{tabular}{lllll}
\hline \multirow{2}{*}{ Injury Severity } & \multicolumn{4}{c}{ Casualty rates for unreinforced masonry structures (\%) } \\
\cline { 2 - 5 } & Slight damage & Moderate damage & Extensive damage & Complete damage \\
\hline Severity 1 & 0.05 & 0.4 & 2 & $10^{*}-50^{* *}$ \\
Severity 2 & 0.005 & 0.04 & 0.2 & $2^{*}-10^{* *}$ \\
Severity 3 & 0 & 0 & 0.002 & $0.02^{*}-2^{* *}$ \\
Severity 4 & 0 & 0 & 0.002 & $0.02^{*}-2^{* *}$ \\
\hline
\end{tabular}

* the smaller values are related to partial collapse of the buildings

** the larger values are given for total collapse (the pancake type of collapse)

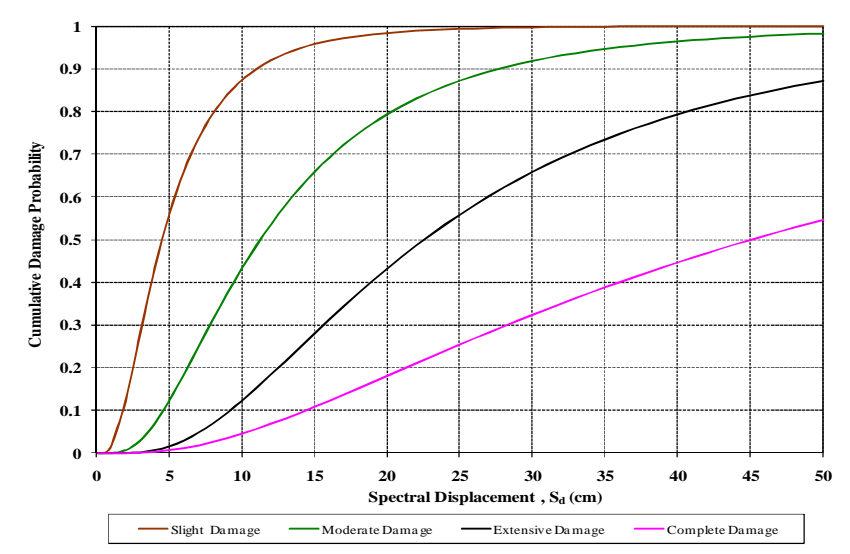

Fig. 17. Example fragility curves for four damage levels.

\section{Casualty assessment}

\subsection{Demographic inventory}

Grid-based demographic data should be provided for casualty estimations. The required level of sophistication with respect to levels of analysis is similar to the building inventory. 30 arc s grid based Landscan (http://www.ornl.gov/sci/ landscan/landscan2005/index.html) population data are provided for Level 0 analysis. The same database is also used as default for Levels 1 and 2. Additionally the Corine population data are provided for countries for which approximate building inventories based on Corine Land Cover are given for Level 1 analysis. For both the Level 1 and Level 2 analyses, if the user desires to estimate casualties based on local data, an additional population field, defining the number of people residing in the cell should be provided together with the building inventory data.

\subsection{Estimation of casualties}

The casualty estimation in Level 2 analysis is based on HAZUS99 and HAZUS-MH methodology. The output from the module consists of a casualty breakdown by injury sever- ity level, defined by a four level injury severity scale (Durkin et al., 1993; Coburn and Spence, 1992a; Cheu, 1995).

Table 3 defines the injury classification scale used in the methodology.

The HAZUS casualty rates were obtained by revising those suggested in ATC-13 (1985) using limited postearthquake fatality data. The casualty model itself is, in fact, based on the models suggested by Coburn and Spence (1992a, b), Murakami (1992) and Shiono et al. (1991). However, unlike other approaches, the methodology is in event-tree format (Fig. 18) and thus capable of taking into account non-collapse-related casualties. To estimate the casualties from structural damage, the model combines a variety of inputs from other HAZUS modules including the probability of being in the damage state and the relationship between the general occupancy classes and the model building type with specific casualty inputs provided for each damage state (D1-slight, D2 moderate, D3 Extensive, D4 Complete, D5 complete with collapse structural damage) in combination with occupancy data and time event.

The probability of suffering $i$-severity $(i=1: 4)$ level is calculated by:

$p_{\mathrm{SI}}=\sum_{k=1}^{5} w_{\mathrm{SI}, k} p_{k}$

where $p_{\mathrm{si}}$ is the probability for people involved in an earthquake to suffer a $i$-severity $(i=1: 4) p_{k}$, is the probability of a damage $D_{k},(k=1: 5)$ occurrence and $w_{\mathrm{si}, k}$ is the casualty rate considered for $p_{k}$ probability.

The expected number of occupants in severity level $i$ $\left(\mathrm{EN}_{i}\right)$ is the product of the number of occupants of the building at the time of earthquake (Noccupants) and the probability of an occupant suffering severity level $i\left(P_{\mathrm{si}}\right)$ :

$\mathrm{EN}_{i}=$ Noccupants $* P_{\mathrm{si}}$

Casualty rates for reinforced concrete and masonry structures as given in HAZUS99 are tabulated in Tables 4 and 5, respectively.

The methodology used in Level 2 for the estimation of number of casualties is the same methodology suggested by 


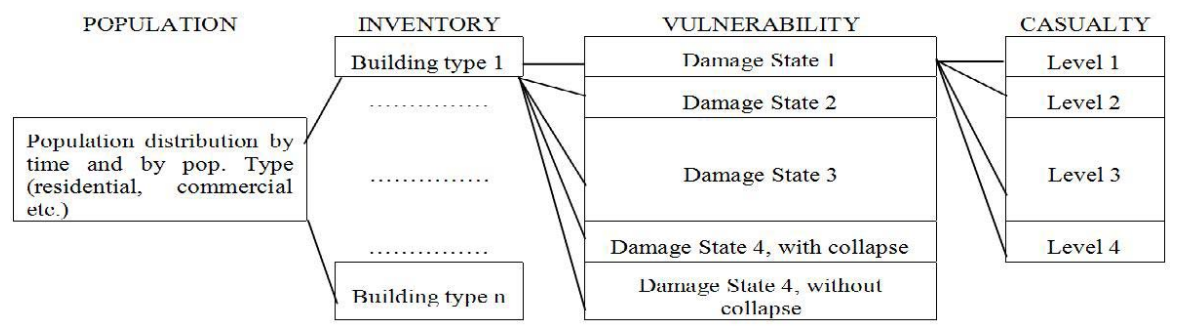

Fig. 18. Event tree being used for the estimation of casualties (Source: HAZUS-MH).

Table 6. Casualty rates for Reinforced Concrete Moment Frame Structures (HAZUS-MH).

\begin{tabular}{lllll}
\hline \multirow{2}{*}{ Injury Severity } & \multicolumn{4}{c}{ Casualty Rates for reinforced concrete structures (\%) } \\
\cline { 2 - 5 } & Slight damage & Moderate damage & Extensive damage & Complete damage \\
\hline Severity 1 & 0.05 & 0.25 & 1 & $5^{*}-40^{* *}$ \\
Severity 2 & - & 0.03 & 0.1 & $1^{*}-20^{* *}$ \\
Severity 3 & - & - & 0.001 & $0.01^{*}-5^{* *}$ \\
Severity 4 & - & - & 0.001 & $0.01^{*}-10^{* *}$ \\
\hline
\end{tabular}

* the smaller values are related to partial collapse of the buildings

** the larger values are given for total collapse (the pancake type of collapse).

HAZUS (1999). If, in addition to the grid based building inventory, a grid-based population distribution is defined by the user, the software computes the number of dwelling units (using user-defined estimated number of dwellings per building type) and an average population per dwelling unit for each cell. Then, casualties for any given building type, building damage level and injury severity level can be calculated by the following equation:

$K_{i j}=$ Population per Building ${ }^{*}$ Number of Damaged

Building in damage state $j^{*}$ Casualty Rate for severity level $i$ and damage state $j$

At present three casualty models are included in ELER. These are HAZUS (1999), HAZUS-MH and the KOERI casualty model for Turkey developed by Erdik and Ayd $\iota$ noglu (2002) using the casualty data from 1992 Erzincan and 1999 Kocaeli earthquakes. Mainly two building types are considered in all three models: reinforced concrete and masonry. The casualty rates given in the three models for these two building types are presented in Table 4 through Table 7. As in Level 1, if a user-defined grid-based population is not available, the program calculates an average population per dwelling unit for the whole study area using the default Landscan population and calculates casualties accordingly.

By changing the population distribution, different casualty estimates may be obtained for different times of the day, such as for a night-time or a day-time scenario.

HAZUS-MH introduced some variations in the casualty rates, especially for the damage states of moderate and com- plete damage with collapse. Casualty rates for reinforced concrete and masonry structures as given in HAZUS-MH are tabulated in Tables 6 and 7, respectively.

\section{Validation and Verification (V\&V) studies}

The analysis methods of the Urban Earthquake Loss Assessment (Level 2) module of ELER software were applied to the selected building types for validation and verification purposes. The damage estimates were compared to the results obtained from the other studies available in literature, i.e. SELENA v4.0 (Molina et al., 2008) and ATC-55 (Yang, 2005). A loss assessment exercise for a scenario earthquake for the city of Istanbul was conducted and physical and social losses were estimated. Damage to the urban environment was compared to the results obtained from similar software, i.e. KOERILoss (KOERI, 2002) and DBELA (Crowley et al., 2004).

\subsection{Comparisons with the other studies}

In order to verify that the methods have been correctly coded into the programming environment and seamlessly implemented by the software, damage estimation results obtained from ELER were compared with those of the SELENA software and of Yang's study. SELENA v4.0- Seismic Loss Estimation Using a Logic Tree Approach (Molina et al., 2008) provides loss estimations for HAZUS model buildings by CSM and MADRS-stiffness degrading hysteretic model. The study by Yang (ATC-55 Project, 2005) computes the 
Table 7. Casualty rates for Unreinforced Masonry Structures (HAZUS-MH).

\begin{tabular}{lllll}
\hline \multirow{2}{*}{ Injury Severity } & \multicolumn{4}{c}{ Casualty Rates for unreinforced masonry structures (\%) } \\
\cline { 2 - 5 } & Slight damage & Moderate damage & Extensive damage & Complete damage \\
\hline Severity 1 & 0.05 & 0.35 & 2 & $10^{*}-40^{* *}$ \\
Severity 2 & - & 0.04 & 0.2 & $2^{*}-20^{* *}$ \\
Severity 3 & - & - & 0.002 & $0.02^{*}-5^{* *}$ \\
Severity 4 & - & - & 0.002 & $0.02^{*}-10^{* *}$ \\
\hline
\end{tabular}

* the smaller values are related with partial collapse of the buildings

** the larger values are given for total collapse (the pancake type of collapse)

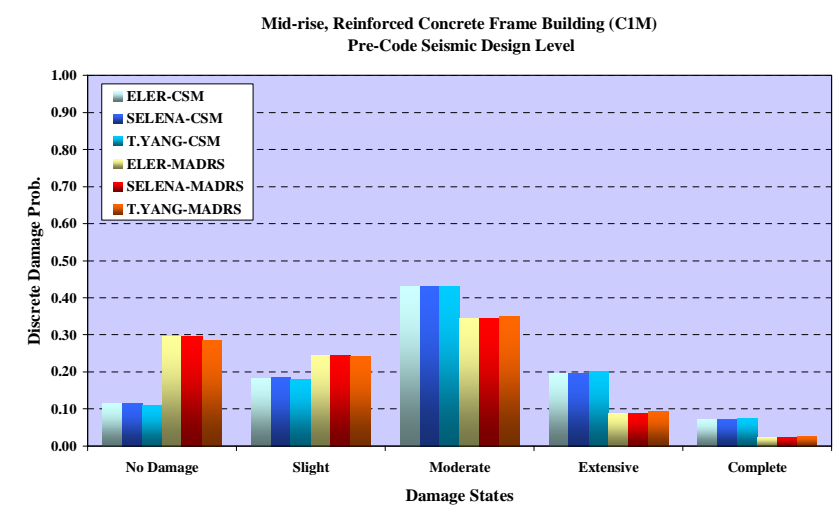

Fig. 19. Discrete damage probabilities calculated by ELER, SELENA and T. Yang's study for building C1M (mid-rise, reinforced concrete frame structure with pre-code seismic design level).

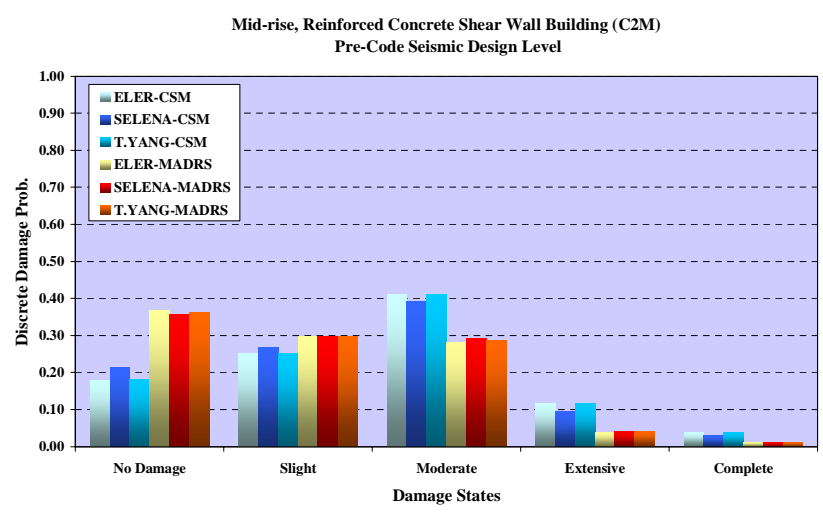

Fig. 20. Discrete damage probabilities calculated by ELER, SELENA and T. Yang's study for building C2M (mid-rise, reinforced concrete shear wall structure with pre-code seismic design level).

performance point for the model building types of HAZUS by CSM and MADRS-approximate equations. Although ELER software provides building taxonomies for both European and HAZUS typologies, it was possible to work solely with HAZUS model building types under two methods.

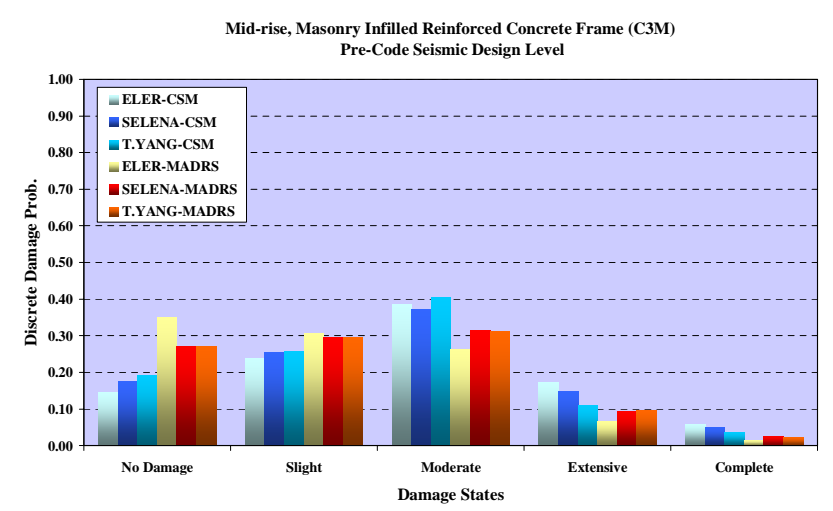

Fig. 21. Discrete damage probabilities calculated by ELER, SELENA and T. Yang's study for building C3M (mid-rise, masonry infilled reinforced concrete frame structure with pre-code seismic design level).

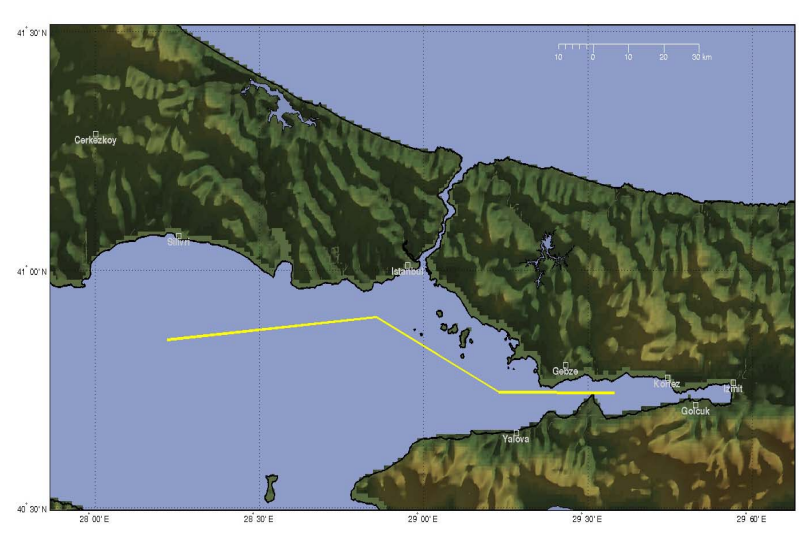

Fig. 22. Ruptured segments of the Main Marmara Fault considered for the Istanbul scenario earthquake: "Credible Worst Case", an $M_{\mathrm{W}}=7.5$ event similar to 1999 Kocaeli Earthquake in magnitude and in total rupture length.

Seismic demand was represented by a specified response spectrum, e.g. Ss $=0.5 \mathrm{~g}, \mathrm{~S} 1=0.25 \mathrm{~g}$ and NEHRP site class B, based on the IBC 2006 spectral shape. Figures 19, 20 and 


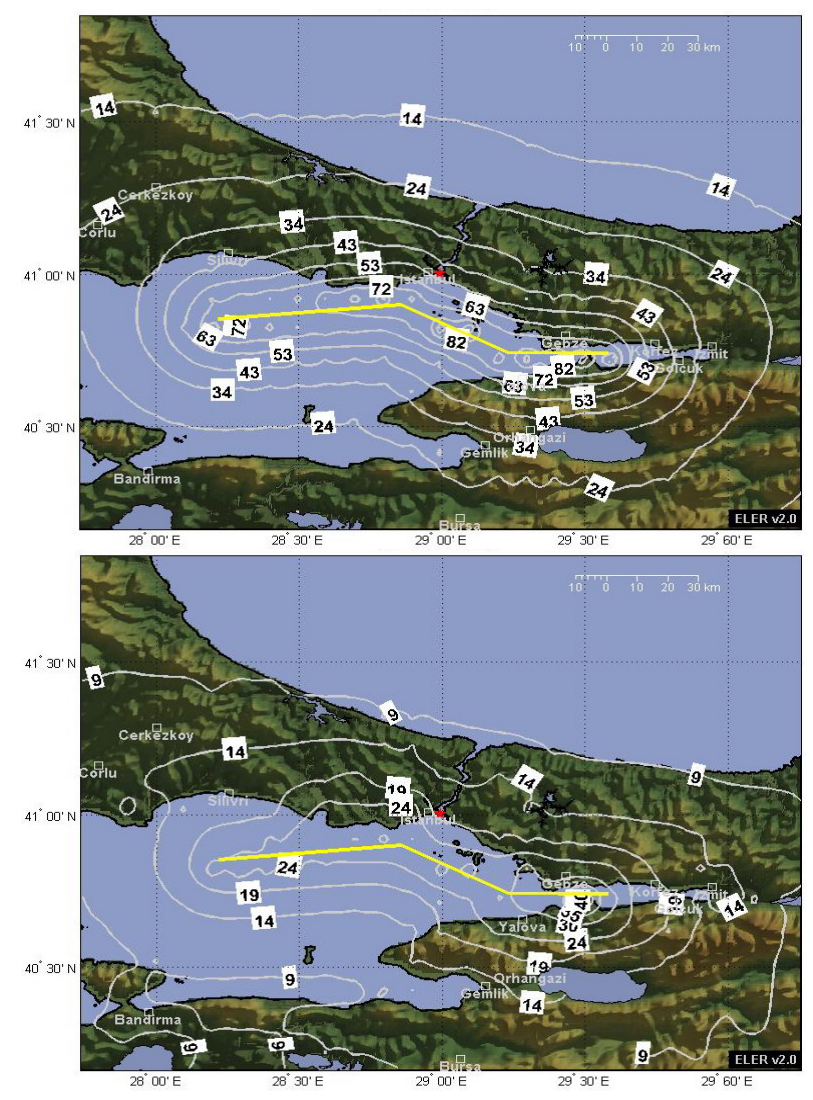

Fig. 23. Shaking maps resulting from the Istanbul scenario earthquake: contours of spectral accelerations, $S_{\mathrm{a}},(\% \mathrm{~g}), S_{\mathrm{a}} @ T=0.2 \mathrm{~s}$ (upper panel) and $S_{\mathrm{a}} @ T=1.0 \mathrm{~s}$ (lower panel).

Table 8. Number of damaged buildings in Istanbul computed by each method of ELER Level 2 module under the $M_{\mathrm{W}}=7.5$ scenario earthquake.

\begin{tabular}{lllll}
\hline Damage Level & CSM & MADRS & RFM & CM \\
\hline Complete & 16675 & 14579 & 10562 & 42611 \\
Extensive & 40912 & 37366 & 28781 & 79152 \\
Moderate & 144780 & 141766 & 112297 & 210885 \\
Slight & 204796 & 212905 & 189994 & 222887 \\
Non & 330483 & 331030 & 396012 & 182111 \\
\hline
\end{tabular}

21 compare the discrete damage probabilities resulting from ELER, SELENA and T. Yang for three different HAZUS model buildings, namely $\mathrm{C} 1-\mathrm{RC}$ frame, $\mathrm{C} 2-\mathrm{RC}$ shear wall and C3-RC frame with infill walls. It was assumed that all three types of buildings were mid-rise structures and corresponded to pre-code seismic design level.

As can be observed from Figs. 19, 20 and 21, all three applications produce highly comparable results.

\subsection{Case study: earthquake loss assessment for Istanbul}

\subsubsection{Shake maps}

An $M_{\mathrm{w}}=7.5$ event (similar to 1999 Kocaeli Earthquake in magnitude and in total rupture length) on the Main Marmara Fault was selected as the "Credible Worst Case" Scenario event for the city of Istanbul. The input ground motion was computed by Hazard module based on the ground motion prediction equation of Boore and Atkinson (2008). The ruptured segments of the Main Marmara Fault are illustrated in Fig. 22 (KOERI, 2002). Figure 23 presents the resulting shaking maps in terms of spectral accelerations.

\subsubsection{Loss estimations}

Damage to built environment was assessed using the same building inventory of the KOERI (2002) study. There were 737646 buildings distributed throughout $0.005^{\circ} \times 0.005^{\circ}$ geo-cells. Classification of the building stock was based on construction type, building height, and construction year. The inventory data were created using the Building Database Creator tool of ELER which allows the introduction of custom building capacity and fragility curves. In order to validate the applicability of the Level 2 module in an urban environment, the building damage probabilities were calculated by CSM, MADRS, RFM and CM. The results are presented in Table 8. Spatial distributions of damaged buildings at each discrete damage state, namely slight, moderate, extensive and complete, are given in Fig. 24.

Assessment of casualties was based on the KOERI and HAZUS-MH models. The spatial distributions of casualties in Severity Levels 3 and 4 which are injuries that pose an immediate life threatening condition if not treated adequately and expeditiously or mortally injured and instantaneously killed people are presented in Fig. 25. The KOERI and HAZUS-MH casualty models produce very different results, where the number of casualties by KOERI model were estimated at 21788 and HAZUS-MH model came up with a number of 3483. This might be due to the fact that KOERI casualty model was developed for Turkey using the damage and casualty data from past earthquakes. It should be noted, at this point, that the user might need to cautiously check the casualty results assessed using default models provided by the software and might prefer working with their own casualty model based on the local past earthquake data, if such is available.

\subsubsection{Comparison with the other software}

A comparative damage estimation exercise under the credible worst case scenario earthquake was also conducted for the Istanbul building inventory. The number of damaged buildings was estimated by three different software packages: ELER, KOERILoss (KOERI, 2002) and DBELA 

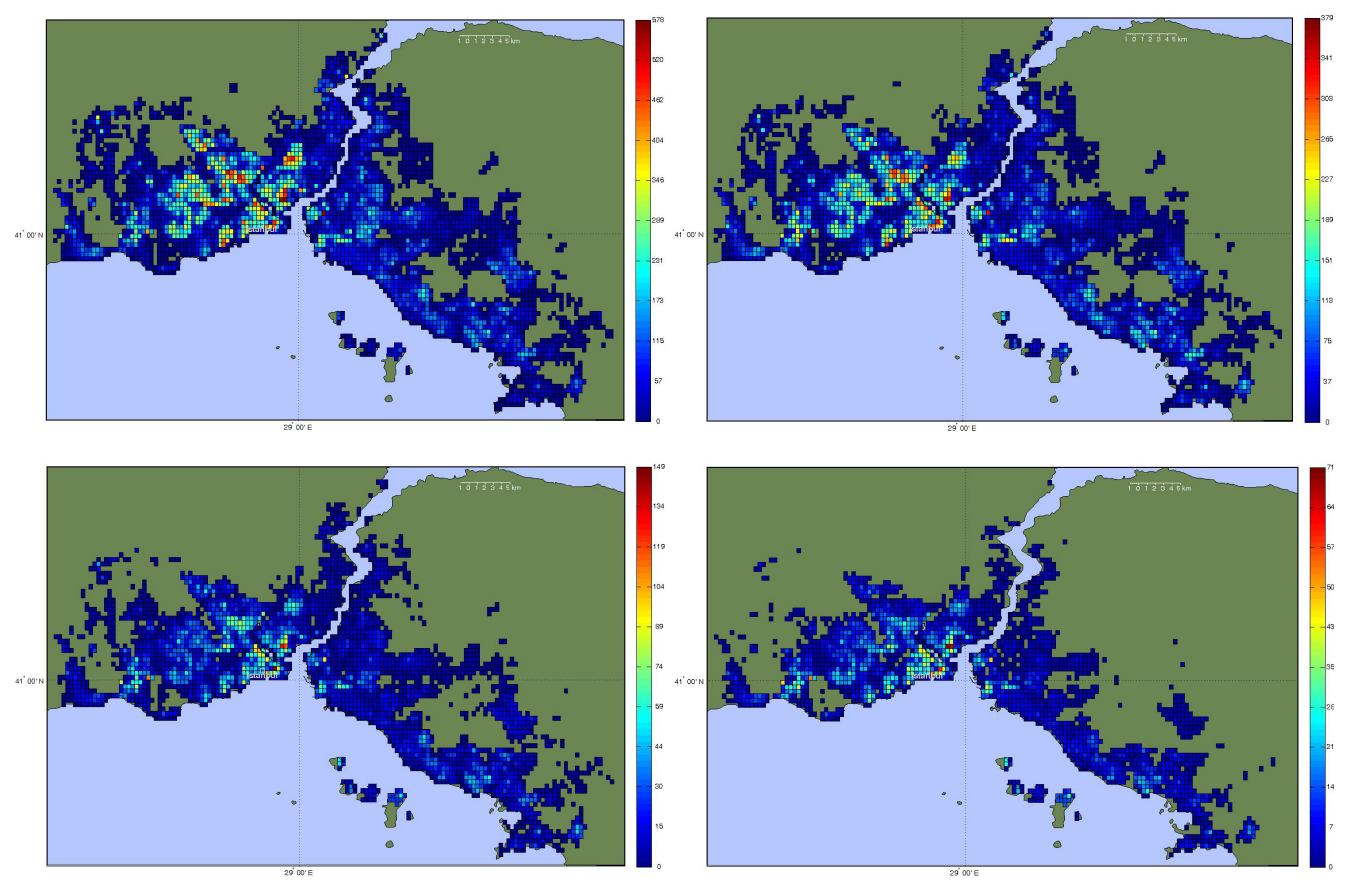

Fig. 24. Distribution of damaged buildings in Istanbul under the $M_{\mathrm{W}}=7.5$ scenario earthquake. Upper panel: slight (left) and moderate damage states, lower panel: extensive (left) and complete damage states.
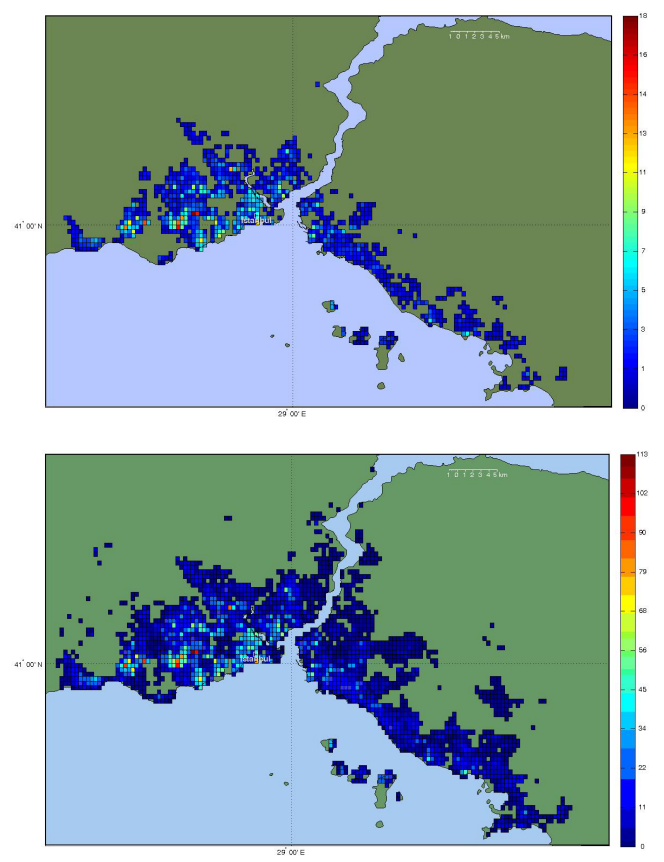

Fig. 25. Distribution of casualties in Istanbul under the $M_{\mathrm{w}}=7.5$ scenario earthquake: people in Severity Level 3 and 4 computed by HAZUS MH model (upper panel) and by KOERI model (lower panel).
(Crowley et al., 2004). The input ground motion was computed as the average of those resulting from the Boore et al. (1997) and Sadigh et al. (1997) ground motion prediction equations. The KOERILoss software follows the displacement coefficient method of FEMA 356 (2000) for the calculation of the performance point and the resulting damage estimates. The DBELA software uses mechanically derived formulae to describe the displacement capacity of classes of buildings (grouped by structural type and failure mechanism) at three limit states. The ELER results were obtained by the Coefficient Method.

The number of damaged buildings is presented in Fig. 26. All three software packages produce highly comparable results, since the methods applied to obtain the performance point are similar and the ground-motion and building-stock data used are identical. It should be noted that the aim of this comparative damage estimation exercise is to validate applicability of the Level 2 module in an urban loss assessment study. It is shown that the Level 2 module of ELER produces results consistent with previous assessments of the seismic risk in Istanbul.

\section{Conclusions}

The potential impact of large earthquakes on urban societies can be reduced by correct and timely action after a disastrous earthquake. The urban earthquake loss assessment module of the ELER (Earthquake Loss Estimation Routine) software, which essentially aims at near real-time assessment 


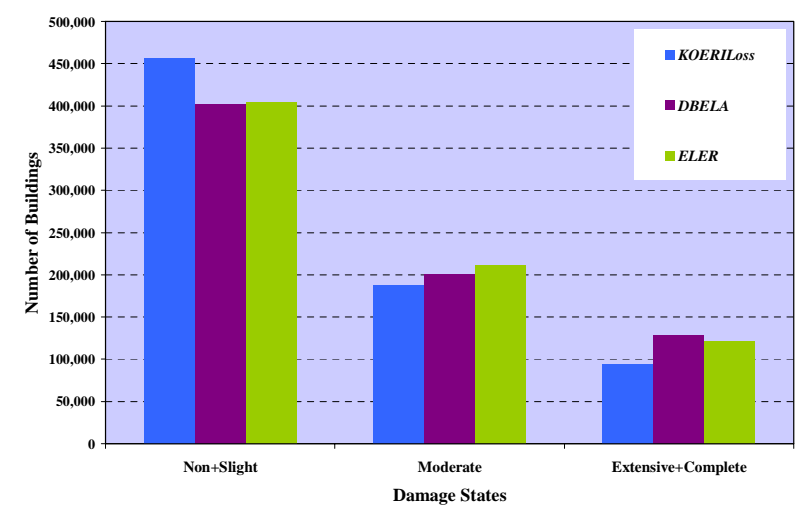

Fig. 26. Comparison of the number of damaged buildings in Istanbul under the $M_{\mathrm{W}}=7.5$ scenario earthquake: calculated by three different software packages, KOERILoss, DBELA and ELER (KOERILoss results taken from KOERI study (2002) and DBELA results taken from Strasser et al., 2008).

of consequences of an earthquake (building damage, consequential human casualties and macro-economic loss quantifiers) in an urban area, is presented. The ultimate goal is the rapid estimation of losses for effective emergency response and public information after potentially damaging earthquakes. Although primarily intended for quasi realtime estimation of earthquake shaking and losses, the routine is also equally capable of incorporating scenario-based earthquake loss assessments and can be utilized for related Monte Carlo type simulations and earthquake insurance applications.

Acknowledgements. For the development of the ELER methodology and software, contribution of the following individuals and institutions is gratefully acknowledged: EC FP6 NERIES Project JRA3 Workgroup: Julian J. Bommer, Peter J. Stafford and Fleur O. Strasser of Imperial College, London, UK, Hilmar Bungum, Dominik H. Lang and Conrad D. Lindholm of NORSAR, Kjeller, Norway, Remy Bossu of European-Mediterranean Seismological Centre, EMSC, Arpajon, France. Furthermore we are also thankful for the support of the following individuals: David Wald of US Geological Survey, USGS, Denver, Colorado, USA, Xavier Goula, Janira Irizarry and Antoni Roca of Institut Geologic de Catalunya, Barcelona, Spain and Alberto Michelini of Istituto Nazionale di Geofisica e Vulcanologia, INGV, Italy. We also express our thanks to the management and engineers of the GRM Risk Management, Inc. that coded and tested the ELER software.

It is gratefully acknowledged that this study is the extended version of the poster paper (Hancilar et al., 2009) awarded by Young Scientist Outstanding Poster Paper (YSOPP) of European Geosciences Union (EGU) General Assembly 2009.

Edited by: O. Katz

Reviewed by: two anonymous referees

\section{References}

Allen, T. I. and Wald, D. J.: Topographic slope as a proxy for seismic site conditions $\left(\mathrm{V}_{s, 30}\right)$ and amplification around the globe, U.S. Geological Survey, Open File Rep., 1357, 69 pp., 2007.

ASCE/SEI 41-06: Seismic rehabilitation of existing buildings, American Society of Civil Engineers, USA, ISBN 9780784408841, 2006.

ATC 13: Earthquake damage evaluation data for California, Applied Technology Council, Redwood City, California, USA, 492 pp., 1985.

ATC 40: Seismic evaluation and retrofit of concrete buildings, Applied Technology Council, Redwood City, California, USA, 612 pp., 1996.

Boore, D. M., Joyner, W. B., and Fumal, T. E.: Equations for estimating horizontal response spectra and peak accelerations from western North American earthquakes: A summary of recent work, Seismol. Res. Lett., 68, 128-153, 1997.

Boore, D. M. and Atkinson, G. M.: Ground-motion prediction equations for the average horizontal component of PGA, PGV, and 5\%-damped PSA at spectral periods between $0.01 \mathrm{~s}$ and 10.0 s, Earthq. Spectra, 24, 99-138, 2008.

Cheu, D. H.: Northridge Earthquake - January 17, 1994: The hospital response, Universal City, CA, FEMA Rep.: Northridge Earthquake: One Year Later, 1-15, 1995.

Coburn, A. and Spence, R.: Factors determining human casualty levels in earthquakes: mortality prediction in building collapse, in: Proceedings of the 10th World Conference on Earthquake Engineering, Madrid, Spain, 5989-5994, 1992a.

Coburn, A. and Spence, R.: Earthquake Protection, John Wiley \& Sons Ltd., Chichester, England, 355 pp., 1992b.

Crowley, H., Pinho, R., and Bommer, J. J.: A probabilistic displacement-based vulnerability assessment procedure for earthquake loss estimation, B. Earthq. Eng., 2, 173-219, 2004.

Crowley, H., Colombi, M., Crempien, J., Erduran, E., Lopez, M., Liu, H., Mayfield, M., and Milanesi, M.: GEM1 Seismic Risk Report: Part 1, GEM Foundation, Pavia, Italy, GEM Technical Rep., 2010-5, 2010.

Demircioglu, M. B., Erdik, M., Hancilar, U., Sesetyan, K., Tuzun, C., Yenidogan, C., and Zulfikar, A. C.: Technical Manual - Earthquake Loss Estimation Routine ELER-v2.0, Bogazici University, Department of Earthquake Engineering, Istanbul, 133 pp., 2009.

Durkin, M. E. and Thiel, C. C.: Towards a comprehensive regional earthquake casualty modelling process, in: Proceedings of National Earthquake Conference of Central U.S. Earthquake Consortium, 557-566, 1993.

EMME Project: Earthquake Model of the Middle East Region, http: //www.emme-gem.org/, 2009-2013.

Erdik, M. and Aydınoglu, N.: Earthquake performance and vulnerability of buildings in Turkey, The World Bank Group Disaster Management Facility Report, 48 pp., 2002.

Erdik, M., Cagnan, Z., Zulfikar, C., Sesetyan, K., Demircioglu, M. B., Durukal, E., and Kariptas, C.: Development of rapid earthquake loss assessment methodologies for Euro-Med region, in: Proceedings of the 14th World Conference on Earthquake Engineering., Beijing, China, S04-004, 2008a.

Erdik, M., Cagnan, Z., Demircioglu, M. B, Durukal, E., Hancilar, U., Harmandar, E., Sesetyan, K., Tuzun, C., Yenidogan, C., and Zulfikar, A. C.: Deliverable 3 (D3), Report on Development 
of ELER (Earthquake Loss Estimation Routine) Methodology: Vulnerability Relationships (http://www.neries-eu.org/main.php/ JRA3_D3_v2.pdf?fileitem=9502731), 2008b.

Erdik, M., Sesetyan, K., Demircioglu, M., Hancilar, U., Zulfikar, C., Cakti, E., Kamer, Y., Yenidogan, C., Tuzun, C., Cagnan, Z., and Harmandar, E.: Rapid earthquake hazard and loss assessment for Euro-Mediterranean region, Acta Geophys., 58, 855$892,2010$.

Erdik, M., Sesetyan, K., Demircioglu, M. B, Hancilar, U., and Zulfikar, C.: Rapid earthquake loss assessment after damaging earthquakes, Soil Dyn. Earthq. Eng., 31, 247-266, doi:10.1016/j.soildyn.2010.03.009, 2011 (published online).

Eurocode 8: Design of structures for earthquake resistance, European Committee for Standardization, Brussels, Draft No. 6, 2003.

Fajfar, P.: A non linear analysis method for performance-based seismic design, Earthq. Spectra, 16, 573-591, 2000.

FEMA 1999: User and technical manuals, Federal Emergency Management Agency, Washington D.C., USA, HAZUS 99, 1999.

FEMA 2003: Technical Manual, Federal Emergency Management Agency, Washington, DC, USA, HAZUS-MH, 2003.

FEMA 356: Pre-standard and commentary for the seismic rehabilitation of buildings, Federal Emergency Management Agency, American Society of Civil Engineers, Reston Virginia, USA, Rep. no. 356, 2000.

FEMA 440: Improvement of nonlinear static seismic analysis procedures, Federal Emergency Management Agency, Applied Technology Council, Washington D.C., USA, Rep. no. 440, 2005.

GEM: Global Earthquake Model, http://www.globalquakemodel. org/, 2010.

Giardini, D., Bossu, R., Eck, T. van, and Wiemer, S.: Networking research infrastructures for earthquake seismology in Europe, EOS T. Am. Geophys. Un., 89, 24, 219, doi:10.1029/2008EO240003, 2008.

Grünthal, G. (Ed.): European Macroseismic Scale 1998, Cahiers du Centre Européen de Géodynamique et de Séismologie. Conseil de l'Europe. Luxembourg, 1998.

Giovinazzi, S.: Vulnerability assessment and the damage scenario in seismic risk analysis, Ph.D. thesis, Department of Civil Engineering of the Technical University Carolo-Wilhelmina at Braunschweig and Department of Civil Engineering, University of Florence, Italy, 2005.

Hancilar, U., Tuzun, C., Yenidogan, C., Zulfikar, C., Durukal, and Erdik, M.: Urban earthquake shaking and loss assessment, EGU General Assembly, Vienna, Austria, EGU2009-6627, 2009.

IBC 2006: International Building Code, International Code Council, USA, 2006.
Kircher, C. A., Nassar, A. A., Kustu, O., and Holmes, W. T.: Development of building damage functions for earthquake loss estimation, Earthq. Spectra, 13, 663-682, 1997.

KOERI 2002: Earthquake risk assessment for Istanbul Metropolitan Area, Bogazici University, Kandilli Observatory and Earthquake Research Institute, Istanbul, Rep. no. 16, http://www.koeri.boun. edu.tr/depremmuh/EXEC_ENG.pdf, 2002.

MATLAB:R2008b, The Math Works, Inc. 2008.

Molina, S., Lang, D. H., and Lindholm, C. D.: User and Technical Manual, SELENA v4.0, NORSAR, Kjeller, Norway, 85 pp., 2008.

Murakami, H. O.: A simulation model to estimate human loss for occupants of collapsed buildings in an earthquake, in: Proceedings of the 10th World Conference on Earthquake Engineering, Madrid, Spain, 5969-5974, 1992.

NERIES Project: Network of research infrastructures for European seismology, The 6th Framework Programme of the European Commission, EC-FP6, http://www.neries-eu.org, 2006-2010.

RISK-UE Project: An advanced approach to earthquake risk scenarios, The 5th Framework Programme of the European Commission, EC-FP5, http://www.risk-ue.net, 2001-2004.

Lagomarsino, S. and Giovinazzi, S.: Macroseismic and mechanical models for the vulnerability and damage assessment of current buildings, B. Earthq. Eng., 4, 415-443, 2006.

Sadigh, K., Chang, C. Y., Egan, J. A., Makdisi, F., and Youngs, R. R.: Attenuation relationships for shallow crustal earthquakes based on California strong motion data, Seismol. Res. Lett., 68, 180-189, 1997.

Sesetyan, K., Demircioğlu, M. B., Kamer, Y., Zulfikar, C., Durukal, E., and Erdik, M.: Regional earthquake shaking and loss estimation, EGU General Assembly, Vienna, Austria, EGU2009-6645, 2009.

Shiono, K., Krimgold, F., and Ohta, Y.: A method for the estimation of earthquake fatalities and its applicability to the global macrozonation of human casualty risk, in: Proceedings of the 4th International Conference on Seismic Zonation, Stanford, CA, USA, 277-284, 1991.

Strasser F. O., Bommer, J. J., Sesetyan, K., Erdik, M., Cagnan, Z., Irizarry, J., Goula, X., Lucantoni, A., Sabetta, F., Bal, I. E., Crowley, H., and Lindholm, C.: A comparative study of European earthquake loss estimation tools for a scenario in Istanbul, J. Earthq. Eng., 12, 246-256, 2008.

Wald, D. J., Worden, B. C., Quitoriano, V., and Pankow, K.: ShakeMap Manual: technical manual, users guide, and software guide, United States Geological Survey (USGS), CA, USA, 2005.

Yang, T.: ATC-55 Project, http://peer.berkeley.edu/ yang/ATC55_ website/, 2005. 